(C) 2016, Elsevier. Licensed under the Creative Commons Attribution-NonCommercial-NoDerivatives 4.0 International http://creativecommons.org/licenses/by-nc-nd/4.0/

\title{
Solar Pond Powered Liquid Desiccant Evaporative Cooling
}

\author{
Esam Elsarrag ${ }^{1}$, Opubo N. Igobo ${ }^{2}$, Yousef Alhorr ${ }^{1}$, Philip A. Davies ${ }^{2}$ \\ ${ }^{1}$ Gulf Organisation for Research and Development, Qatar Science and Technology Park, Doha, Qatar, email: \\ e.elsarrag@gord.qa \\ ${ }^{2}$ Sustainable Environment Research Group, School of Engineering and Applied Science, Aston University, \\ Birmingham, B4 7ET, UK email: p.a.davies@aston.ac.uk
}

\begin{abstract}
Liquid desiccant cooling systems (LDCS) are energy efficient means of providing cooling, especially when powered by low-grade thermal sources. In this paper, the underlying principles of operation of desiccant cooling systems are examined, and the main components (dehumidifier, evaporative cooler and regenerator) of the LDCS are reviewed. The evaporative cooler can take the form of direct, indirect or semi-indirect. Relative to the direct type, the indirect type is generally less effective. Nonetheless, a certain variant of the indirect type - namely dew-point evaporative cooler - is found to be the most effective amongst all. The dehumidifier and the regenerator can be of the same type of equipment: packed tower and falling film are popular choices, especially when fitted with an internal heat exchanger. The energy requirement of the regenerator can be supplied from solar thermal collectors, of which a solar pond is an interesting option especially when a large scale or storage capability is desired.
\end{abstract}

Keywords: Liquid desiccant, dehumidifier, evaporative cooling, regenerator, solar pond

\section{CONTENT}

1. Introduction

2. Liquid desiccant evaporative cooling

$2.1 \quad$ Liquid desiccant materials

General

Water absorption theory

2.2 Thermodynamic cycles used for liquid desiccant cooling

Desiccant-direct evaporative

Indirect evaporative

Regenerative

Recirculation of internal air

Mixing with external air

2.3 Different types of components used

Dehumidifiers

Evaporative coolers

Regenerators

3. Solar pond

3.1 Non-convective solar ponds

3.2 Convective solar ponds

3.3 Design of solar ponds

3.4 Examples of solar ponds

4. Conclusions 


\section{Introduction}

Temperature and humidity of ambient air are two critical factors that determine comfort levels of occupants in a given space. In hot climates, it is desirable to reduce the ambient air temperature (cooling) to improve comfort levels; however in hot and humid climates (as in some Gulf countries), removal of moisture from the air (dehumidification) is almost as important as cooling [1]. Besides occupant discomfort, insufficient dehumidification can also adversely result to mould and mildew growth. ASHRAE Standard 55 [2] recommends temperature $19-28{ }^{\circ} \mathrm{C}$ and less than $65 \%$ relative humidity for comfort conditions.

Conventional air conditioning systems (for example vapour compression systems) address these issues by cooling air below its dew point such that water vapour condenses on a cooling coil, thus removing moisture from the air. The dehumidified air is then reheated to the desired temperature [3]. This process of deep cooling to dew point and reheating consequently leads to higher energy requirement. Alternatively, desiccants can be employed to use their hygroscopic properties to dehumidify the air [4, 5]. Studies have reported that desiccant systems can reduce energy consumption by as much as $40 \%[6-8]$.

Desiccants are natural or synthetic substances, having a high affinity for water, capable of absorbing water vapour from their immediate vicinity. They are available in both liquid and solid states. Solid desiccants are compact and less corrosive. On the other hand, liquid desiccant offer several benefits, including, lower regeneration temperature, lower pressure drop of air across the desiccant material, suitability for dust removal by filtration, and flexibility in utilisation especially when handling large volumes of air [9-11].

In desiccant cooling cycles, the desiccant (brought into contact with air) reduces the humidity of the air by absorbing moisture from the air. Then the air temperature is reduced by conventional cooling coils or other components such as evaporative coolers [12]. However, the moisture impregnated desiccants need to be dried in a regenerator, in which the water vapour previously absorbed evaporated out from it by heating. The heat required to regenerate the desiccant can be supplied from low-temperature sources [13] such as waste heat or solar energy. Utilizing solar energy for this application is particularly interesting because the greatest demand for cooling occurs during times of highest solar insolation. There are different means by which the solar thermal energy can be harnessed for this purpose; examples include conventional solar thermal collectors, solar ponds, and salt works. Besides collecting solar thermal energy, solar ponds have the inherent ability of also storing the thermal energy, and have been widely studied as such. 
This paper will review the technologies used for desiccant cooling systems and solar ponds; different options will be compared and evaluated (in the preliminary sense) with regards to complexity, cost and performance, for the operating conditions prevalent the Gulf region. Also, specific technical risks and challenges will be identified and assessed for systematic appraisal. Figure 1 below shows the proposed system that combines the solar pond, the seawater bittern desiccant and the indirect/direct evaporative cooling.

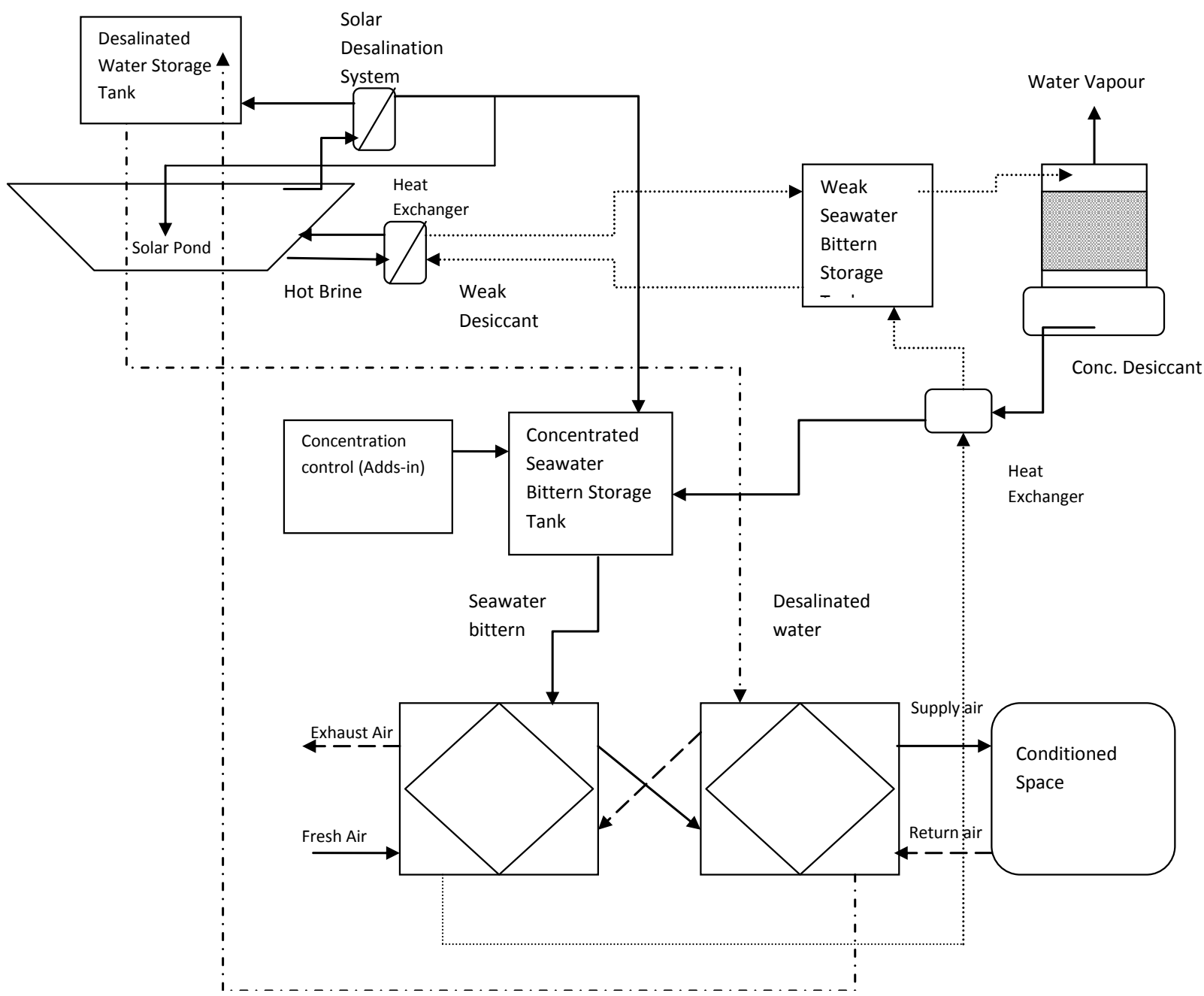

Fig. 1: Schematic of the proposed system (GORD TechnoHub)

\section{Liquid desiccant evaporative cooling}

\subsection{Liquid desiccant materials}

Desiccant materials play a crucial role in the development of desiccant air conditioning. The characteristics of the desiccant material being utilized impact the performance of the desiccant air conditioning systems significantly [14]. Materials for the liquid desiccants should have low vapour pressure, low viscosity and good heat transfer characteristics. The surface tension of liquid desiccant 
is also important as it directly influences static hold up and wetting of desiccant air contact surface [15]. Commonly used desiccants include aqueous solutions of lithium chloride, calcium chloride, lithium bromide and triethylene glycol. Other desiccants include seawater bitterns, $\mathrm{MgCl}_{2}$ [16], $\mathrm{KCOOH}$, glycols like triethylene glycol (TEG), diethylene glycol (DEG), MEG, propylene glycol, and mixtures of desiccants $\mathrm{LiCl}+\mathrm{LiBr}$ or $\mathrm{LiCl}+\mathrm{CaCl}_{2}[15,17]$.

One key principle for selecting appropriate desiccant materials is that the desiccant materials should possess largely saturated adsorption amount and can be reactivated easily. The water absorption capacity of a desiccant solution depends on its equilibrium vapour pressure which in turn depends on its temperature and concentration. The higher the concentration and lower the temperature, the higher would be the moisture absorption capacity. But at high concentrations and low temperatures, there is an adverse possibility of crystallization of the desiccant. Therefore, different desiccants have different optimum operating concentration levels, e.g. $55-60 \%$ for lithium bromide, 30-45\% for lithium chloride, $35-45 \%$ for $\mathrm{CaCl}_{2},<35 \%$ for $\mathrm{MgCl}_{2}$, and $95-97 \%$ for TEG $[18,19]$.

The ethylene glycols are material friendly, in that, they are not corrosive and do not crystallize during the dehumidification process. However, they are quite prone to evaporating into the air stream. Brines (especially $\mathrm{LiCl}$ and $\mathrm{CaCl}_{2}$ ) are a popular choice though having the drawback of been corrosive and crystallizing at concentrations higher than $40 \%$ [20]. The physical properties of some common desiccants are compared in Table 1.

Table 1. Physical properties of common liquid desiccants at $25^{\circ} \mathrm{C}$

\begin{tabular}{|c|c|c|c|c|}
\hline $\begin{array}{c}\text { Desiccant by } \\
\text { weight }\end{array}$ & $\rho .10^{-3}\left(\mathrm{~kg} / \mathrm{m}^{3}\right)$ & $\mu .10^{3}\left(N_{S} / m^{2}\right)$ & $\gamma \cdot 10^{3}(\mathrm{~N} / \mathrm{m})$ & $C p .\left(k J / k^{\circ} C\right)$ \\
\hline 95\% TEG [21] & 1.1 & 28 & 46 & 2.3 \\
\hline $\begin{array}{c}5 \% \text { LiBr }[22] \\
\text { Error! } \\
\text { Reference } \\
\text { source not } \\
\text { found. } \\
\end{array}$ & 1.6 & 6 & 89 & 2.1 \\
\hline $40 \% \mathrm{CaCl}_{2}[23]$ & 1.4 & 7 & 93 & 2.5 \\
\hline $40 \% \mathrm{LiCl} \quad[24]$ & 1.2 & 9 & 96 & 2.5 \\
\hline
\end{tabular}

Note. $\rho$ - density; $\mu$-viscosity; $\gamma$ - surface tension; $C p$ - specific heat

Desiccant mixtures have been proposed in order to combine the advantages of the individual components and to improve the overall characteristics of the desiccant. For example, in an attempt to obtain a liquid desiccant with lower cost than aqueous lithium chloride, but more stable than calcium chloride, aqueous solutions containing a mixture of these two salts have been investigated by Etras et al.Error! Reference source not found. [24]. They calculated the heat and mass transfer coefficients for the desiccant air systems in a packed bed absorption tower using empirical correlation 
from the literature. Three desiccants were compared: lithium chloride, calcium chloride and mixture of both lithium and calcium chlorides. The mixture solution was found to improve the mass transfer greatly compared to the calcium chloride solution while the heat transfer coefficients in liquid side were similar for the three salt solutions.

In addition to dehumidification, an added benefit of the desiccants is that they are capable of absorbing inorganic and organic contaminants in the air. The absorption process has the potential to remove biological pollutants such as bacteria, fungi and viruses so improving indoor air quality [25, 26]. However, in some circumstances, there is a benefit in adding a desiccant dehumidifier to the cooling system to control humidity separately from air temperature. The benefits are greater where the moisture loads are high compared to the sensible heat loads, or where they peak at different times [27].

\subsection{Thermodynamic cycles used for liquid desiccant evaporative cooling}

The schematic of a typical liquid desiccant cooling system is depicted in Fig. 2. The system is composed of three major components, namely, the dehumidification unit, regeneration unit and cooling unit (heat exchanger evaporative coolers) [28]. The liquid desiccant is pumped into the dehumidification unit, where it is distributed over a large surface area and comes in contact with the humid air stream from which it absorbs moisture. The resulting diluted desiccant is fed to the regeneration unit to re-concentrate the diluted solution to an acceptable concentration for reuse, so as maintain continual operation of the cycle. The cooling unit cools the dehumidified air; this could take the form of direct evaporative cooling and/or indirect evaporative cooling [29], in accordance to the desired comfort level. Direct evaporative cooling is simply when water evaporates into the air to be cooled, simultaneously humidifying it, as it is been cooled. In contrast, for indirect evaporative cooling, the air to be cooled is separated from the evaporation process, by a heat exchange membrane, such that it is cooled without been humidified. 


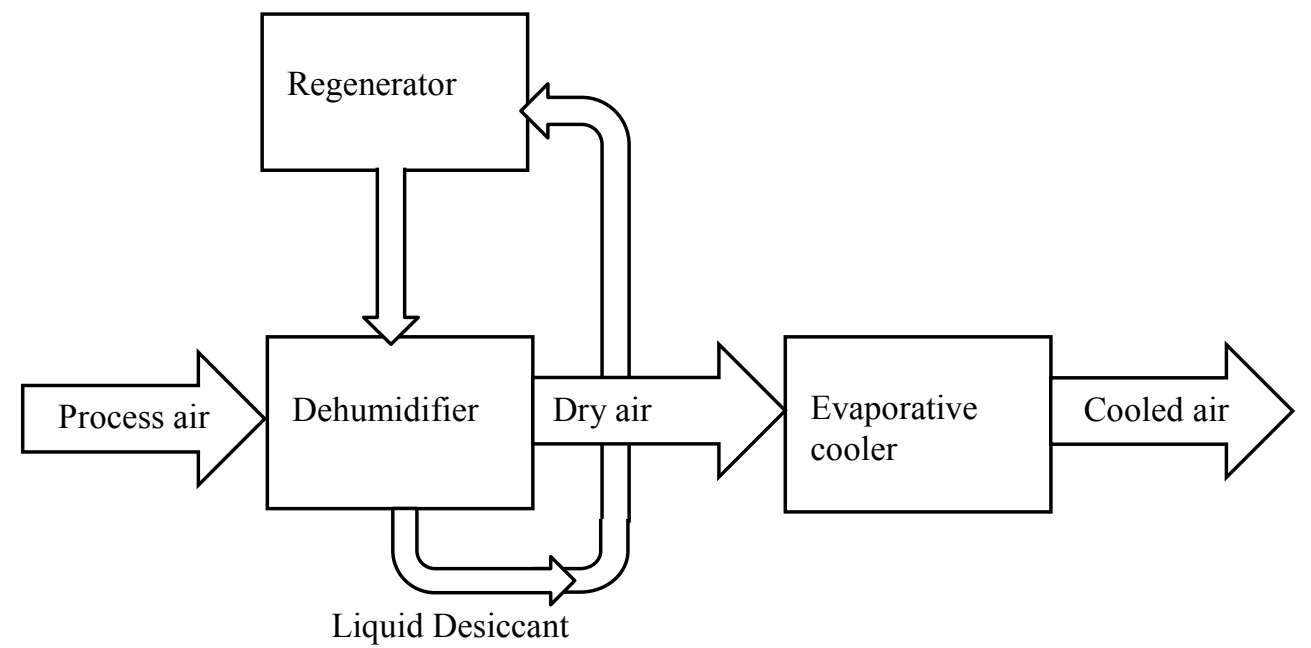

Fig. 2: Schematic of basic liquid desiccant evaporative cooling [28]

The liquid desiccant cooling system can be deployed in diverse technological arrangements/configurations. The most common configuration uses a desiccant stage preceding a direct evaporative stage. However alternative configurations can include indirect evaporative stages or heat recuperative/recovery stages. There are also choices as regards recirculation of internal air and mixing with external fresh air.

Some heat recuperative/recovery configurations employ heat exchanger to use the return air from the indoor conditioned space to pre-cool the dehumidified air before it is evaporatively cooled [30]. Another heat recuperative approach commonly encountered is the linking of the absorber and regenerator via a liquid-to-liquid heat exchanger to reduce the regenerator residual heat dumping back to the conditioner. Here, the cool dilute desiccant from the outlet conditioner was used to precool the warm concentrated solution transferred from the regenerator to the conditioner. This improved the dehumidifier performance and also reduces the heat input to the regenerator by $10-15 \%$ [15].

A complete configuration of a desiccant evaporative cooling system was presented by Elsarrag et al. [31]. In the proposed system, a wide range of outdoor air flow rates were used (450 to $1000 \mathrm{~m}^{3} / \mathrm{h}$ ). In their configuration, the outside air was initially cooled and dehumidified by the desiccant and then cooled via a direct evaporative cooler. A supply air temperature as low as $19^{\circ} \mathrm{C}$ was obtained in a hot, humid climate.

A configuration incorporating both direct and indirect evaporative coolers was presented by Tu et al. [32]. In the proposed system, process air from the atmosphere was first dehumidified by the dehumidifier and then cooled without any moisture content variation in an indirect evaporative cooler, where the exhaust air from the air-conditioning space was utilized as the secondary air. Finally, the 
process air was cooled in a direct evaporative cooler adiabatically. Because the cooling energy of exhaust air was already recovered in the indirect evaporative cooler to the process air, air recirculation was not necessary.

A configuration involving the recirculation of internal air and mixing with external fresh air was studied by Kessling et al. [33]. In the configuration (Fig. 3), the outside air was dehumidified and mixed with returning indoor air; the mixed air was then cooled in an indirect evaporative cooler and resupplied to the conditioned space. However, before being delivered to the room, a part of the mixed air was diverted as the secondary air to provide the evaporative cooling, and then released as exhaust.

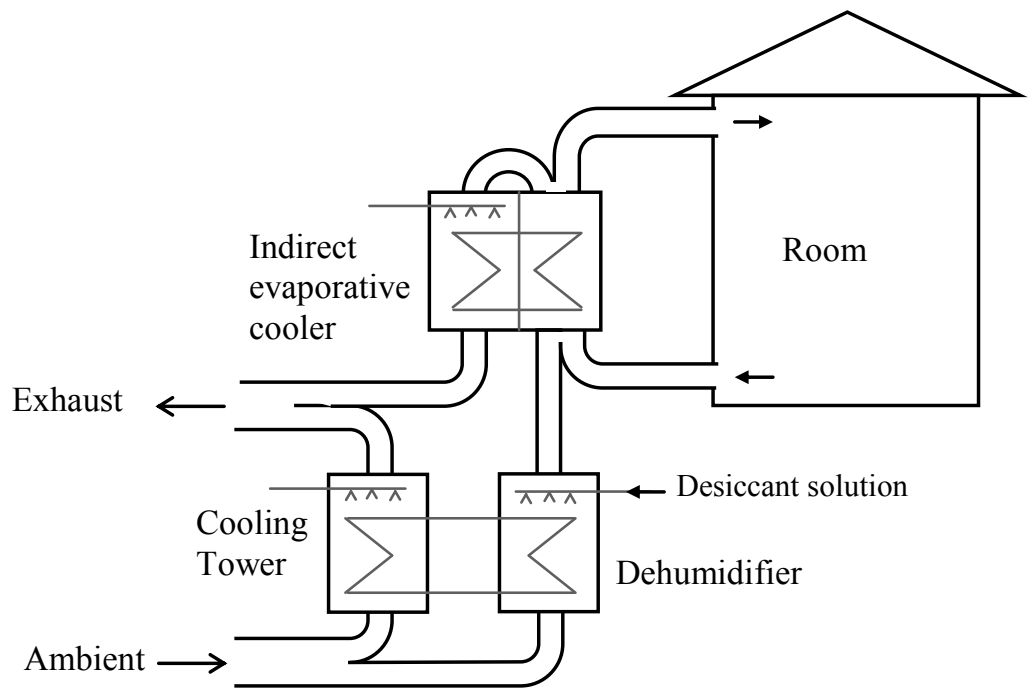

Fig. 3: Schematic of liquid desiccant cooling configuration with indirect evaporative cooling of external air mixed with recirculating internal air [33]

A configuration that involved the combination of bits of all the configurations above was presented in ref [34]. There (Fig. 4), the return air from the cooled room was divided into three portions; the first part of the return air was dehumidified, and then cooled by adiabatically saturated outside air in a heat exchanger (indirect evaporative cooling - IEC). The dehumidified air then underwent direct evaporative cooling (DEC) before being mixed with recirculated air (the second portion of the air returned from the cooled room) and pre-cooled fresh air (the fresh air was pre-cooled by the third part of the return air in a heat recovery exchanger). The mixture was then introduced into the conditioned space to satisfy both the sensible and the latent loads. The diluted desiccant solution (leaving the dehumidifier) was preheated in a liquid-liquid heat recovery exchanger, before entering the regenerator. The simulation showed that the influence of the heat recovery from the regenerator far exceeded those from the other heat exchangers involving these air streams. 


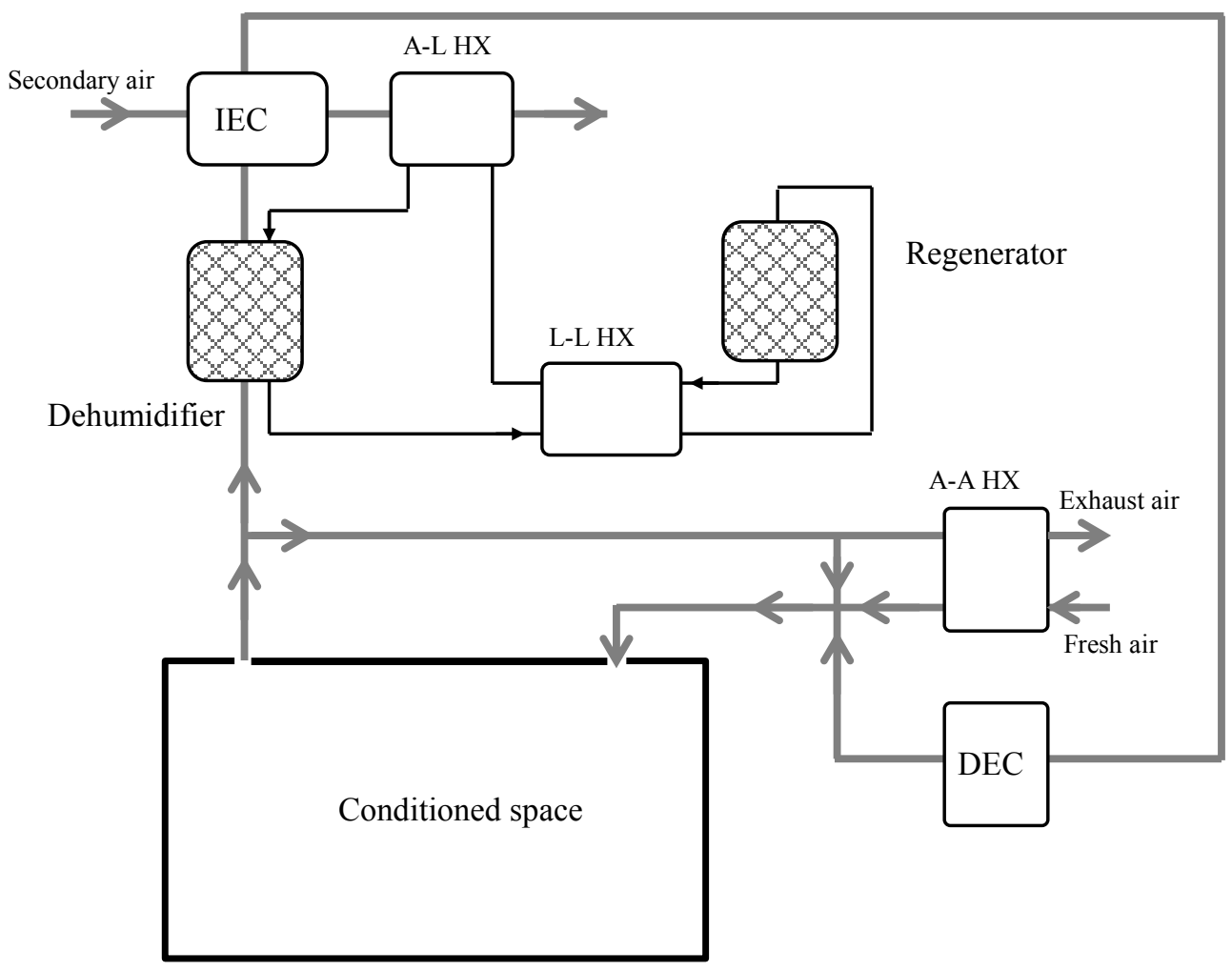

Fig. 4: Schematic of liquid desiccant cooling system with a combination of configurations [34]

\subsection{Different types of components used}

The equipment used for the different components of a desiccant system are air-contacting equipment for liquid-air interactions designed for enhanced heat and mass transfer for handling the low liquid flow and large process air flow rates, with minimal air pressure drop, while providing the desired large contact surface area [15]. In many compact configurations, the dehumidifier and the regenerator are made of a similar type of equipment $[35,36]$. An important issue of concern in the design of the contacting equipment is the undesirable phenomenon of carryover of some molecules/droplets of desiccant along with the air stream [37]. Besides resulting in monetary losses over time, large quantities of carryover can also pose serious health hazards [38]. A good dehumidifier/regenerator system should minimise carryover as much as possible. In the following sub-sections, each component is reviewed separately concerning the above considerations.

\subsubsection{Dehumidifiers}

The principal component of liquid desiccant dehumidification systems is the inside geometry of the absorber (i.e.,. the kind of packing) employed. The basic configurations commonly encountered mainly include spray tower, packed tower and falling film arrangements [39]. To compensate for the 
adverse temperature rise during the dehumidification process, the desiccant could be externally cooled before entering the dehumidifier or better still internally cooled within the dehumidifier to improve performance $[40,41]$. This can be implemented by having coils or plate heat exchangers as an integral part of the dehumidifier.

The performance of the dehumidifier can be expressed in terms of the dehumidifier effectiveness/efficiency, moisture removal rate, or mass transfer coefficient [18, 42-44]. The dehumidifier effectiveness is the ratio of the achieved change in the humidity level of the air exiting the dehumidifier, to the maximum theoretical change.

$$
\varepsilon_{d}=\frac{w_{\text {in }}-w_{\text {out }}}{w_{\text {in }}-w_{\text {equ }}}
$$

Where $w_{\text {in }}$ and $w_{\text {out }}$ are the water contents of the inlet and outlet air streams respectively; while $w_{\text {equ }}$ is the water content of the air which is at equilibrium with the desiccant solution at the inlet concentration and temperature.

The moisture removal rate, $m_{w}$, can be given in terms of the air flow rate, $\dot{m}_{a}$, as [44]

$$
m_{w}=\dot{m}_{a}\left(w_{a, \text { in }}-w_{a, \text { out }}\right)
$$

The mass transfer coefficient $K$ (for vapour phase) can be obtained from empirical correlations in terms of non-dimensional parameters Sherwood number $(S h)$, Reynolds number $(R e)$ and Schmidt number $(S c)$ [45].

$$
\begin{gathered}
K a\left(\frac{M_{w} d_{e q}^{2}}{D_{v a} \rho_{a}}\right)=S h \\
S h \propto \operatorname{ReSc} \frac{L}{G}
\end{gathered}
$$

Where, $d_{e q}$ is equivalent diameter in the dehumidifier; $M_{w}$ is the molecular weight of water; $D_{v a}$ is the water vapour's diffusion coefficient in air; $\rho_{a}$ is the density of the air, $a$ is the packing's specific surface area; $L$ and $G$ are the mass flux of the liquid desiccant and air respectively.

\subsubsection{Spray Tower}

In spray tower arrangement, gas (air) usually flows upwards, while liquid (the desiccant solution) is fed from the top of the tower through the spray nozzle. The nozzles are used to break the liquid down into small droplets, such that in operation, the gas and liquid interact over the outside surface of the small liquid droplets; thus providing large surface area for heat and mass transfer. The spray towers 
have the merits of simplicity, low cost, and low air side pressure drop, however, their major drawbacks are low absorption effectiveness and large carryover [15].

In minimizing carryover, conventional spray chambers employ dense cellulose pads (demisters) to restrict the liquid droplets from escaping the chamber [46], however, this adversely increases the pressure drop on the air side [38]. To overcome this issue, different techniques have been proposed.

Kumar et al. [38] proposed using stainless steel wire mesh to eliminate the carryover. Experimental results show improvement in performance of conventional spray tower by about $30 \%$ without increasing air side pressure drop.

To enhance the mass transfer rate and to avoid carryover of liquid particles, Chung and $\mathrm{Wu}$ [47] proposed a "U-shape" tunnel spray tower with eliminators in the spray tower. Unlike in conventional arrangements, the air was introduced from the top of the tower to contact the liquid particles cocurrently. This co-current contact of air and solution reduced the carryover of liquid particles. In an experimental study of the design, with $95 \%$ TEG desiccant solution, it was observed the mass transfer coefficient increases linearly with an increase in air flow rate. The achieved mass transfer coefficients varied from 1.78 to $2.95 \mathrm{~mol} / \mathrm{m}^{3} \mathrm{~s}$, corresponding to heights of a single transfer unit of 0.63 to $0.38 \mathrm{~m}$, respectively. The efficiencies of the spray tower typically varied from 64 to $86 \%$. In a later study [48], they presented empirical correlation of the mass transfer coefficient as:

$$
S h=4.0 * 10^{-5} \operatorname{Re}^{1.73} S c^{0.33}\left(\frac{P_{S}}{P_{\text {total }}}\right)^{-0.5}\left(\frac{L}{G}\right)^{1.15}
$$

\subsubsection{Packed tower}

The packed tower consists of a column packed with materials having a large surface to volume ratios. To promote mass transfer, it is desired that the desiccant wet the packing and spread evenly over its surface. Considerations for the choice of packing materials for the dehumidification process include pressure drop, sensitivity to fouling, liquid holdup, ease of handling high or low desiccant flow rate, resistance to corrosion and cost [49].

The materials may be packed in random or structured patterns. The random packing may employ different or same materials and sizes. Examples include polypropylene Pall rings, partition rings, glass Raschig rings, flexi rings, Lessing rings, Berl saddles, Tellerettes, and ceramic Intalox saddles. These types of random packing materials offer large contact area in a relatively small volume compared to structured packing, thus facilitating more mass transfer. However, they generally cause high air pressure drop [50]. 
On the other hand, structured packing exhibits high efficiency and high capacity for mass and heat transfer, in contrast to the traditional random packing. They have shown excellent performance characteristics with a relatively low ratio of pressure drop to heat and mass transfer coefficient per unit volume, in addition to easy installation [50]. Examples of structured packings include cellulose rig pads, wood grids, expanded metal lash, double spiral rings. Some commonly structured packings types can also be categorised as gauze type and sheet types. These packings can be arranged as corrugated sheets, such that air and liquid flowing between adjacent sheets undergo periodic redistribution within the packing.

Gandhidasan [49] developed a model for estimating the pressure drop in a packed tower dehumidifier for both random and structured packings. Three different structured packing materials (Gempack 2A, sheet-type Mellapak $250 \mathrm{Y}$ and Gauze type) and four random materials (Pall rings, Berl saddles, Raschig rings and Intalox saddles) were considered in the analysis. It was shown that among random packing materials the Intalox saddles can give the least pressure drop while among the structured packings, the sheet type (mellapak $250 \mathrm{Y}$ ) promised the least pressure drop.

Abdul-Wahab et al. [51] experimentally studied the effect of the effect of packing densities, on the performance of dehumidifier with structured packings of arrays of stacked plates and TEG desiccant solution. Lower dehumidification effectiveness was observed for the higher packing density, as a result to poor wetting conditions in high packing density.

Elsarrag [52, 53] Error! Reference source not found.conducted theoretical and experimental studies of the simultaneous heat and mass transfer to evaluate a packed dehumidifier effectiveness using high outdoor air flow rates. Due to packing arrangements, the tested dehumidifier showed high efficiency ( $80 \%$ to $90 \%$ ), low pressure drop and minimum solution carry over. In his previous study [54], the mass transfer coefficient was empirically correlated within $+/-15 \%$ as.

$$
S h=6.18 * 10^{-6} \operatorname{Re}^{1.3} S c^{0.33}\left(1-\frac{P_{S}}{P_{w}}\right)^{-0.77}\left(\frac{L}{G}\right)^{0.55}
$$

Incidentally, the method of distributing the liquid over the packed tower could also influence the performance as observed by Patnaik et al. [55]0. Two methods of liquid distribution, namely: gravity tray distributor and spray nozzle system where studied. Higher capacities (40 - 50\% increase) and lower pressure drop $(30-40 \%$ reduction) for the air flow were observed with the spray system. 


\subsubsection{Wetted wall (falling film) column}

Wetted wall/falling film column arrangements consist of a set of tubes (Fig. 5a) or plates (Fig. 5b) over which desiccant solution flows down by gravity while air is blown through it. The liquid flows as thin film over the vertical surfaces represented by the tubes or plates, and the air is brought into contact with the surface of flowing liquid film. Besides having low pressure drop and low initial cost, these columns also provide large contact surface area per unit volume [56]. However, in practice there is the difficulty of ensuring a thin film over the entire surface, especially for large towers $[57,58]$. The measure of the degree of wetness achieved is termed wetness factor or wettability, and can influence the performance of the system. Studies have shown that the wettability can be enhanced using micro/nano scale surface treatment [59]. The experimental study by Kim et.al [59] emphasised that as a result of the improved wettability achieved on roughened tubes, higher heat and mass transfer performances was observed for the roughened tubes (relative to smooth tubes).
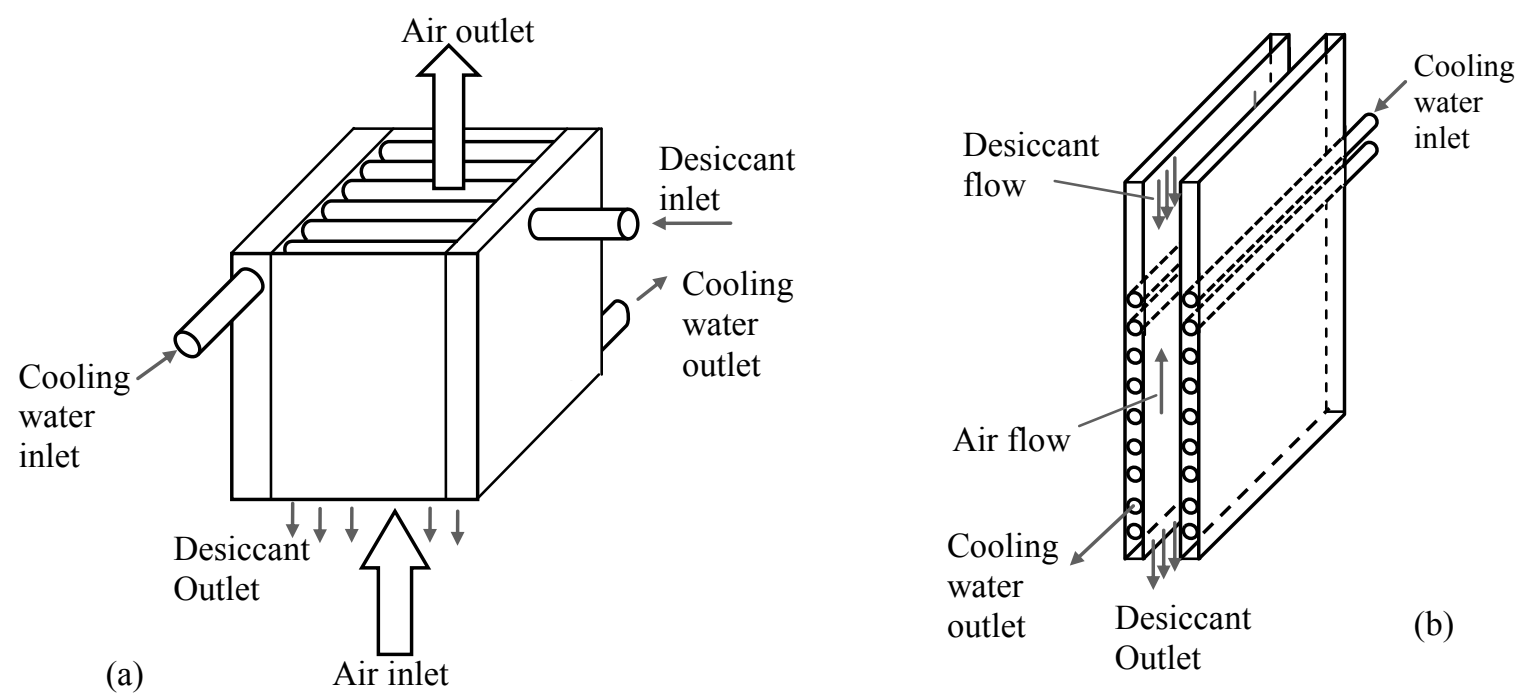

Fig. 5: schematics of wetted wall falling film system [60]; 0(a) tube type (b) plate type

Besides tube surfaces, the plate type arrangements are widely studied in the literature [60-62]. The plates could be flat or corrugated, and the arrangements are often internally cooled. A typical internally cooled plate dehumidifier could entail cooling water circulated in polypropylene double plates involved an upward airflow and a downward solution flow. A special distributor of liquid desiccant on top of each plate could help the solution flow uniformly over the exchanger surface. The performance of plate dehumidifiers systems can be influenced by the setup of the system.

Ali et al. [63] performed a comparative study between air and falling desiccant solution film in parallel and counter-flow configurations, with nanoparticles suspensions ( $\mathrm{Cu}$-ultrafine particles) added to the desiccant solution to investigate the heat and mass transfer enhancements. The numerical 
results showed that, for a wide range of parameters, the parallel flow arrangement indicated better dehumidification and cooling of the air, than the counter-flow channel. This was said to be a result of the exit humidity ratio and air temperature being lower in the parallel flow arrangement than in the counter flow. However, elsewhere [64], counter flow arrangement has been shown to provide better performance.

Furthermore, a study by Park et al. [65] found that a decrease in the mass flow rate of the air resulted in a better control of the humidity ratio and lower temperature for the air. Yigit [27] obtained the heat and mass transfer coefficients of the absorption process in a falling film LiBr-water absorber. This author also studied the effect of varying coolant flow rate, solution flow rate and coolant temperature on the absorber performance. Deng and Ma [66] used a falling film absorber that was made up of 24 horizontal rows of smooth tubes. The results showed that while the mass transfer coefficient was increased with the increase of the spray density, the heat transfer coefficient was increased only in a small spray density range.

Other kinds of performance enhancement have also included the adoption of fin heat exchangers in the implementation of internally cooled film dehumidification, taking the form of plate-fin-heat exchanger (PFHE) [56, 67] or fin-tube heat exchanger [68].

To further enhance performance, some designs adopt evaporative cooling in the internal cooling channels of the absorber. Here, a standard plate heat exchanger, PHE, with several flow passages separated from each other by thin plastic plates, is employed such that dehumidification is carried out on one side of the plate, while evaporative cooling is concurrently effected on the other side, in a cross flow manner. Each thin plate, besides separating the water-air passage from the solution-air passage, also provides a contact area for heat and mass transfer between the fluids flowing in each passage. Saman and Alizadeh [69] conducted numerical analysis and indicated that the dehumidification efficiency of the PHE increases as the solution mass flow rate increases and up to $85 \%$ efficiency could be achieved at an optimal primary air velocity of about $0.7 \mathrm{~m} / \mathrm{s}(0.3 \mathrm{~kg} / \mathrm{s})$ however; the performance achieved in an experimental study by Alizadeh [70] was only about $60 \%$. Furthermore, an experimental study by Saman and Alizadeh [71] indicated the performance of the system is also dependent on the angle of inclination of the PHE, with an optimal angle about $25-45^{\circ}$.

\subsubsection{Other novel systems}

A novel rotary absorber system was patented by Riffat [72]; the proposed system employed flexible fibre needle-impeller rotors/fan to improve heat and mass transfer in the absorber (and evaporator) units. Unlike in conventional desiccant systems, it is possible to achieve a large transfer area per unit 
volume. The fan could perform the function of the absorber (or evaporator) by feeding the fibres with a desiccant solution (or water) [73]. Oliveira et.al [74] studied the system experimentally, and developed a model for characterizing its performance in different system parameters.

Another novel rotary contacting device, in a rotating disc configuration (Fig. 6), was studied by Lowenstein et.al [75]. Besides high surface area density and low air side pressure drop, a salient characteristic of this system that distinguishes it from conventional ones is its relatively very low flows of liquid desiccant (typically 20 times lower), making it less prone to carryover.

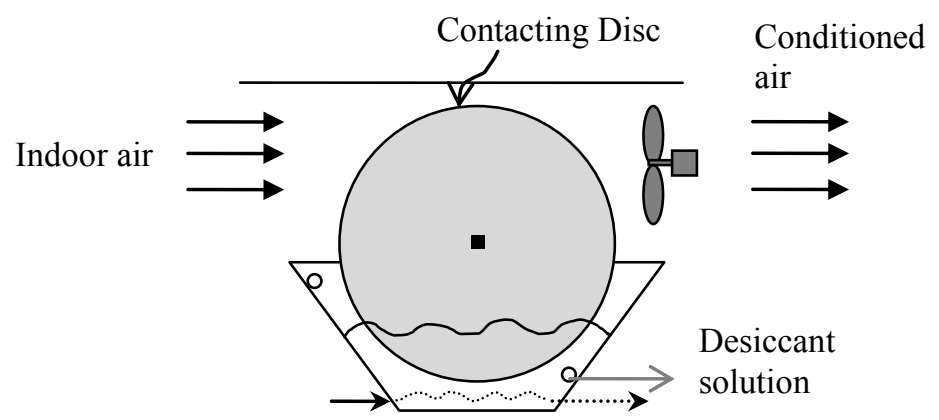

Fig. 6: Rotating disc air contacting device [76]

Another dehumidification technology that has been considered extensively to address the desiccant droplets carry over phenomenon, involve indirect contact, employs semi-permeable membrane, separating the air and liquid desiccant streams, such that only water vapour is allowed to permeate from the air to the liquid stream, but prevents the transport of liquid.

A further dehumidification technology that has been extensively considered to address the liquid desiccant droplets carry over phenomenon involves indirect contact between the air and liquid streams via a hydrophobic semi-permeable micro-porous membrane, which allows only water vapour to permeate while preventing the transmission of liquid, thus eliminating the desiccant carryover problem [77-81]. Researchers have proposed membrane designs such as flat plate type [82-86] or hollow tube fibre type [87-90]. Though the flat plate membrane type is simpler in construction, the hollow fibre membrane type promises relatively better effectiveness, due to the latter's considerable higher packing density [91]. Studies $[92,93]$ have highlighted that although considerable vapour flux could be obtainable with the membranes, the dehumidification effectiveness was generally low, as the membranes offered resistance to mass transfer. 


\subsubsection{Evaporative cooler}

Although evaporative cooling systems can be built in a variety of arrangements or configurations, as introduced earlier (in section 2.2) they are no more than various combinations of three basic types, namely: direct evaporative cooling (DEC), indirect evaporative cooling (IEC), and semi-indirect evaporative cooling (SIEC).

\subsubsection{Direct evaporative coolers}

Direct evaporative cooling (DEC) is the oldest and simplest type of evaporative cooling and involves bringing the process air into direct contact with water. One of the main evaporative cooling strategies often encountered is the fan-pad system [94]. The fan-pad arrangement includes a fan/blower and an evaporation pad (example include: metal pads, cellulose pad, organic pad, inorganic pad (GLASdek, PVC pad, etc.) which provides the needed large surface area over which the air and water are contacted for effective evaporation. Often these coolers have the fan, the pad and ancillary systems all enclosed in a box (Fig. 7), such that the pad is kept moist by continuously dripping water unto the upper edges of the pad, the water gets distributed further by gravity and capillary action. The falling water is collected in a water basin underneath the pad and recirculated by a water pump [95]. The drip-type coolers are the cheapest and simplest evaporative coolers but have some problems including pad clogging, pad scaling. Alternatives, requiring less maintenance (though at a higher cost) are Slinger-type, sprayed-pad and rotary-pad evaporative coolers [96].

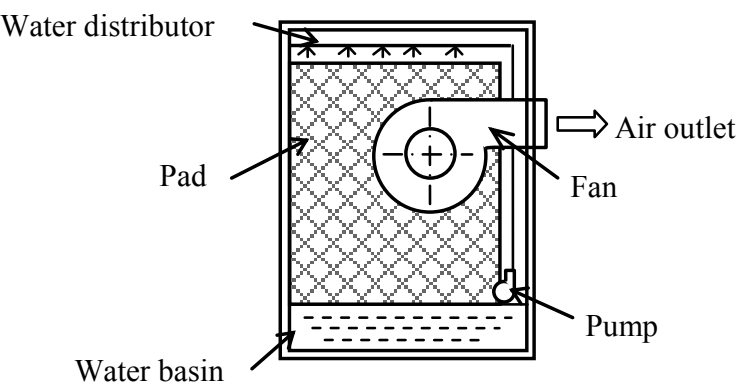

(a)

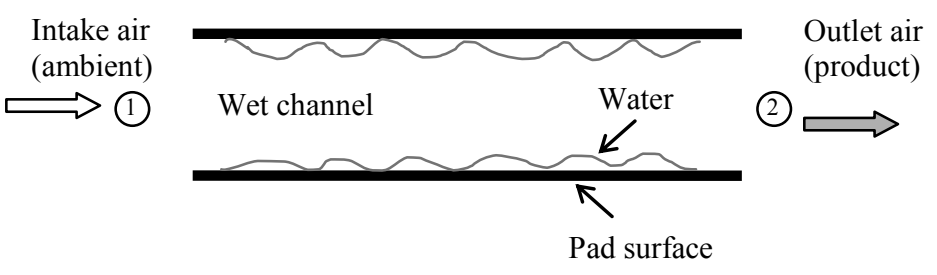

(b)

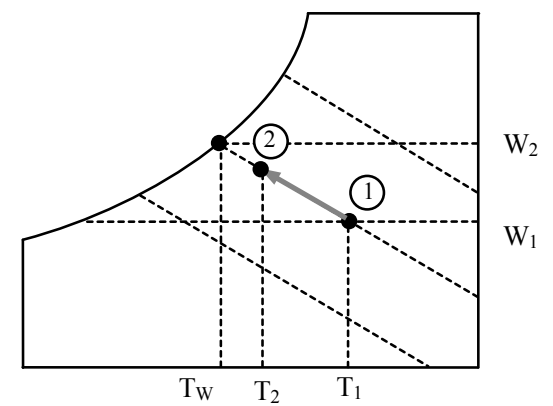

(c)

Fig. 7: (a) Schematic of drip-type DEC [95]; (b and c) typical air and water interaction and psychrometric process [97] 
The performance of DEC can be indicated with the cooling or saturation efficiency or effectiveness, generally defined in terms of the wet-bulb temperature

$$
\eta_{w b}=\frac{T_{\text {in }}-T_{\text {out }}}{T_{\text {in }}-T_{w b}}
$$

Where, $\eta_{w b}$ is the wet-bulb effectiveness, $T_{i n}$ and $T_{w b}$ are respectively the dry-bulb and wet-bulb temperatures of the air at the inlet condition, while $T_{\text {out }}$ is the dry-bulb temperature at the outlet of the system. Most of the existing commercial DEC coolers in market can achieve 70-95\% saturation efficiency.

\subsubsection{Indirect evaporative coolers}

Besides the air to be cooled (primary air), indirect evaporative coolers (IEC) employ a secondary air stream that is brought in direct contact with water and have the resulting cooling effect transferred via heat exchange medium to the primary air; i.e. a direct evaporative cooled secondary air stream is used to cool indirectly a primary air stream. Depending on the kind of heat exchanger employed, IEC can be categorised as tubular type IEC, plate type IEC and heat pipe type IEC as depicted in Fig. 8(a) - (c) respectively. Since the primary air does not make direct contact with water in the IEC, the temperature of the primary air decreases without a change in its absolute humidity as shown the psychrometric chart (Fig 8e).

The wet-bulb effectiveness of IEC can be expressed in terms of the wet-bulb temperature of the secondary air as

$$
\eta_{w b}=\frac{T_{\text {in }}-T_{\text {out }}}{T_{\text {in }}-T_{w b, s e c}}
$$

Where, $T_{\text {in }}$ and $T_{\text {out }}$ are the inlet and outlet dry-bulb temperatures of the primary air respectively; while $T_{w b, s e c}$ is the inlet wet bulb temperature of the secondary air. The effectiveness of IEC is generally around $50-70 \%[98]$. 

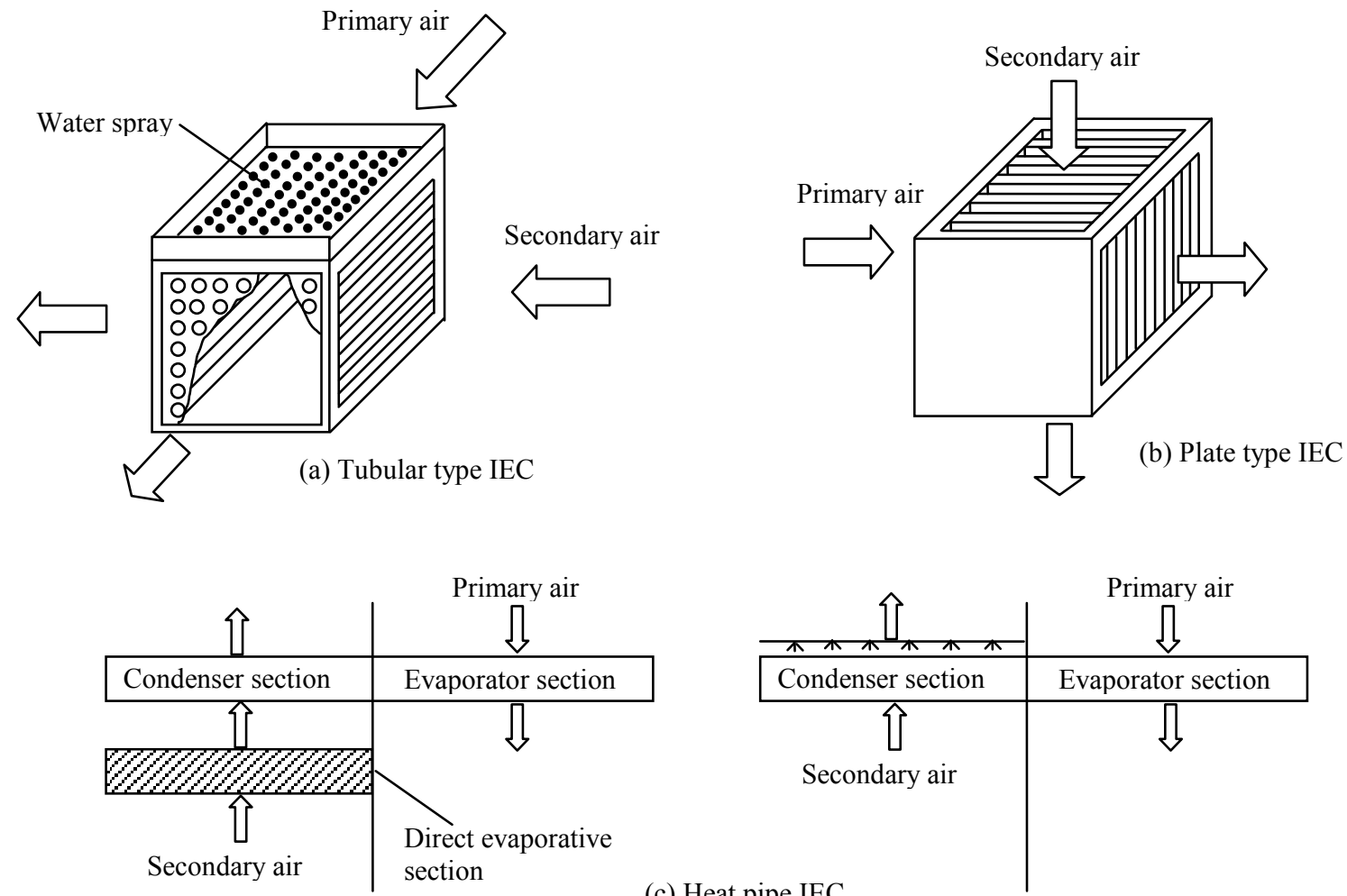

(c) Heat pipe IEC
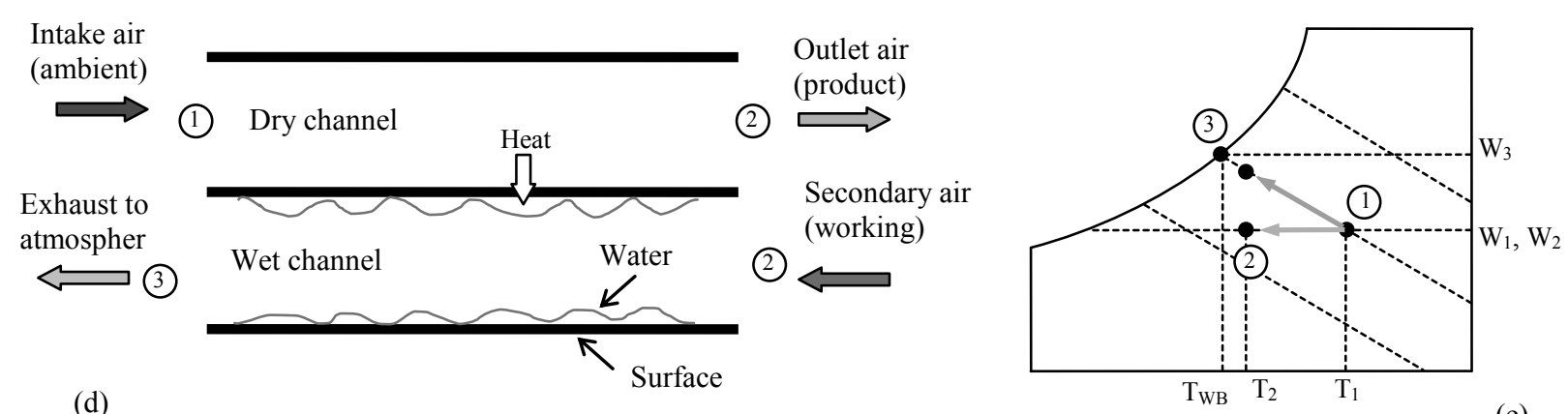

Fig. 8 (a-d) Schematics of IEC and (e) psychometric process [95, 97]

\subsubsection{Semi-indirect evaporative coolers}

Semi indirect evaporative cooler (SIEC) employ porous materials such as porous ceramic tubes or hollow bricks [99] to effect heat (and mass) transfer. A typical schematic of the system is depicted in Fig. 9. Water (and secondary air) is contained/flow inside the channel/hollow of the material while the primary air flows over the outside surface. The porosity of the material allows the water inside the tube/brick to be capillary transported through the walls to the outside surface of the material, where it evaporates into the primary air if its vapour pressure is higher than that of the air (thereby acting as a DEC). However, if the vapour pressure of the outdoor air is higher than that of the water at the 
surface, the system works merely as an IEC. Thus the heat and mass transfer is between the processes of DEC and IEC [100]. And the wet-bulb effectiveness of the system can be obtained as outline earlier, and could be in the range of $40-80 \%$ [98].

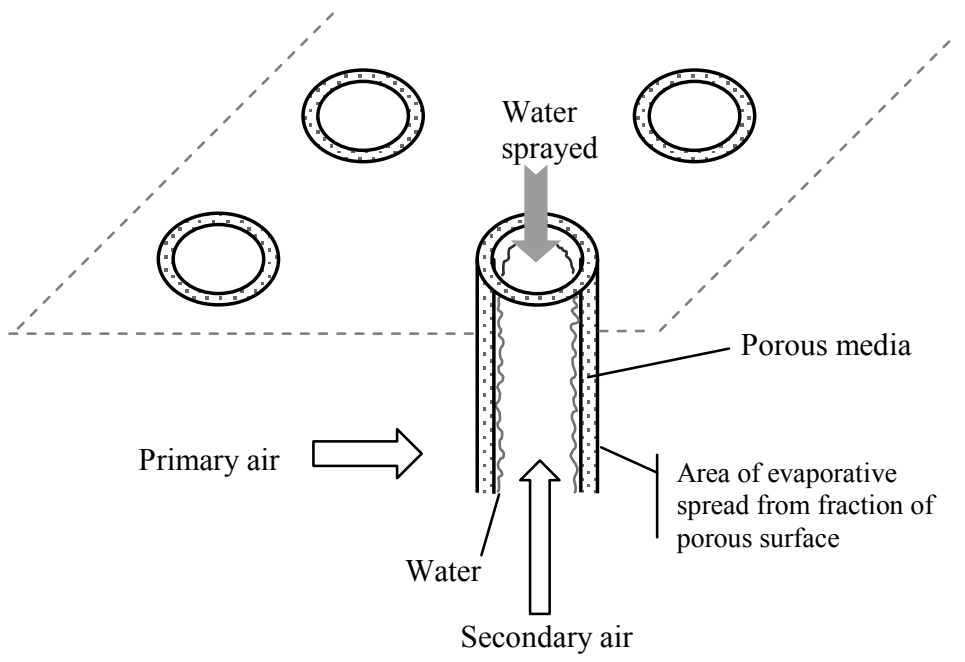

Fig. 9: Schematic of an SIEC [101]

\subsubsection{Dew point indirect evaporative (DPEC) cooling}

Dew point evaporative cooling is somewhat a configuration of indirect evaporative cooling comprising adjacent wet and dry air passages/channels. It consists of specially made plates that are designed to wick water evenly on side and transfer heat through the other side; there are numerous holes distributed in the air flow channels of the incoming working air [102, 103] (Fig. 10). On operation, the working air initially enters dry channels and is fractionated into multiple streams which are directed into the wet channels through the holes. However, some variants (often called regenerative evaporative coolers) do not have holes but redirect a portion of the air exiting the dry channel into the wet channel [104-106]. As a result of evaporation, the air in the wet channel absorbs heat from the product air flowing in the adjacent side. This process occurs multiple times in a short physical space within the exchanger, thus, resulting in progressively colder product air temperatures [107]. 

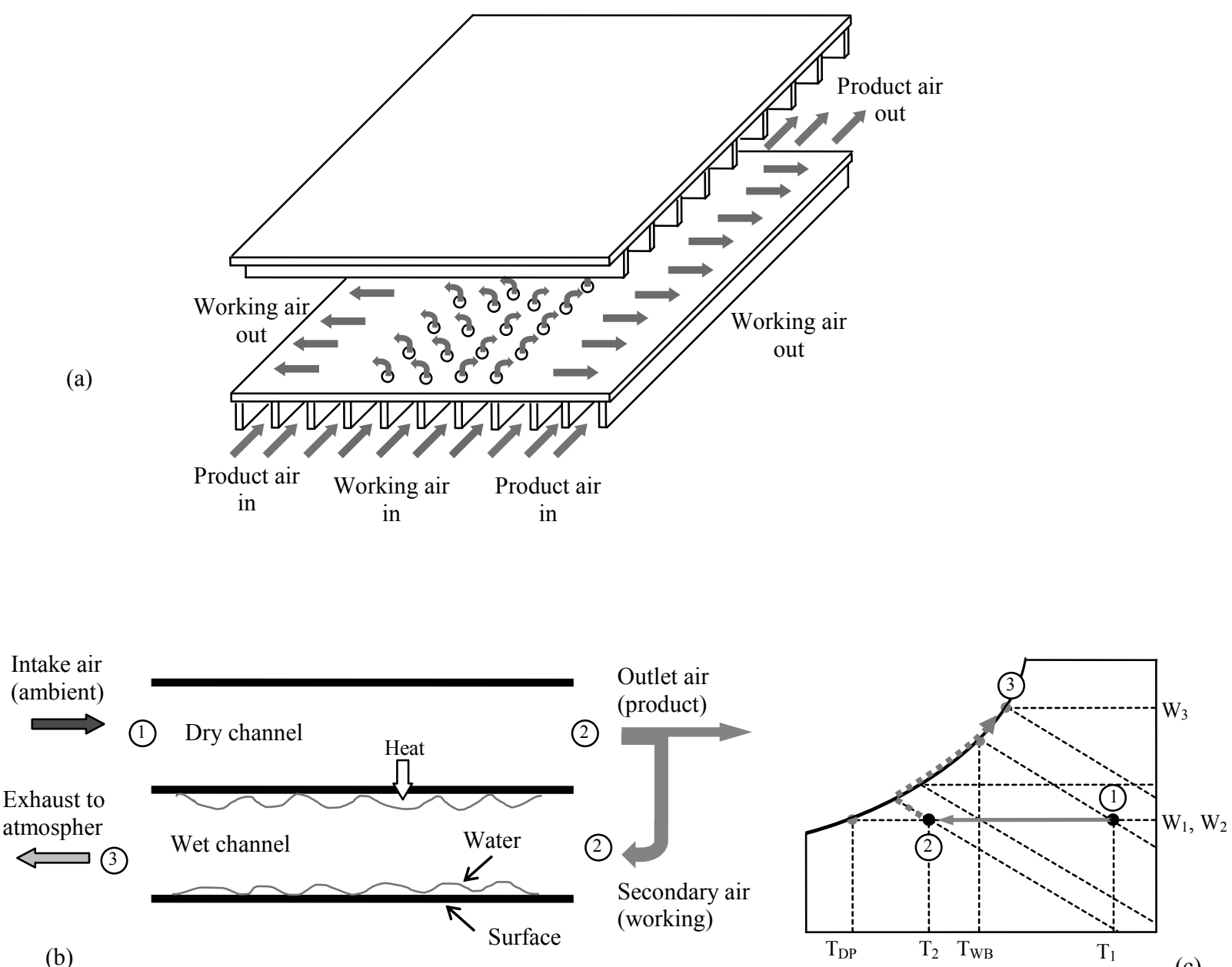

Fig. $10(a, b)$ schematics of DPEC and (c) psychometric process [97, 107]

The arrangement enables the temperatures of the product air to be cooled nearly to the dew-point temperature of the incoming working air, which is considerable lower than the wet bulb temperature (the achievable limit for direct evaporative cooling) [108].

For DPEC, the saturation efficiency can be expressed based in terms of dew point temperature as

$$
\eta_{\text {dew }}=\frac{T_{\text {in }}-T_{\text {out }}}{T_{\text {in }}-T_{\text {dew }, \text { in }}}
$$

Where, $T_{\text {in }}$ and $T_{\text {out }}$ are the inlet and outlet dry-bulb temperatures of the product air, $\mathrm{T}_{\text {dew,in }}$ is the dewpoint temperature of the working air at the inlet. Generally, the dew point saturation efficiency can be between $55-85 \%$, however, the wet-bulb efficiency (based on the wet-bulb temperature) can be as high as $110-122 \%$ [97]. 
The DPEC has been studied by several researchers [98, 109, 110]. Zhan [111] found that for optimum

performance, the optimum flow rate ratio of working-to-product air was about $50 \%$, and the dimensionless channel length (ratio of channel length to height) should be between 100 to 300. And it has also been shown to exhibit greater (over 15\%) cooling effectiveness, when operated in counter flow configuration compared to cross flow [109].

Cui et al. [112] simulated the behaviour of a DPEC and presented correlations for the heat and mass transfer coefficients. The mass transfer coefficient $\left(h_{m}\right)$ was given in terms of the Sherwood number correlation as

$$
S h=\frac{h_{m} D_{p}}{D_{v a}}=2.0+0.6 R e^{1 / 2} S c^{1 / 3}
$$

While the heat transfer coefficient $(h)$ was given in terms of Nusselt number, $N u$, correlation as

$$
N u=\frac{h D_{p}}{k_{a}}=2.0+0.6 \operatorname{Re}^{1 / 2} \operatorname{Pr}^{1 / 3}
$$

Where, $D_{p}$ is the diameter of particle water droplet; $k_{a}$ is the thermal conductivity of air, $\operatorname{Pr}$ is Prandtl number.

\subsubsection{Regenerators}

As explained above, evaporative coolers are employed to cool the dehumidified air from the dehumidification unit; however the liquid desiccant employed to effect the dehumidification gets diluted in the process and thus needs to be re-concentrated by a regenerator before being reused. The regenerator is a very crucial heat and mass transfer component in a liquid desiccant system. The heat used for the desiccant regeneration represents the largest energy requirement associated with the liquid desiccant system; hence the overall system performance can be greatly influenced by the effectiveness or efficiency of the desiccant regeneration process [113].

The effectiveness of the regenerator can be given of the change in moisture content of the air stream flowing through the regenerator [114]

$$
\varepsilon_{\text {re }}=\frac{w_{\text {out }}-w_{\text {in }}}{w_{\text {out } \text { max }}-w_{\text {in }}}
$$


Alternatively, the effectiveness can also be given in terms of the change in concentration of the desiccant solution flowing through [115]:

$$
\varepsilon_{r e}=\frac{C_{s, \text { out }}-C_{s, \text { in }}}{C_{s, \text { sat }}-C_{s, \text { in }}}
$$

Where $C_{s, i n}$ and $C_{s, o u t}$ are the concentrations of the desiccant solutions flow in and out of the regenerator respectively, while $C_{s, s a t}$ is the concentration of the saturation solution at the given average temperature of the regenerator.

Elsarrag and Abdalla [116] presented a new regenerator effectiveness definition based on the desiccant properties and assessed experimentally. The definition may be helpful to the regenerator designers to evaluate the effectiveness using the air and solution vapour pressures, the proposed definition and the presented correlation are shown below respectively.

$$
\begin{gathered}
\varepsilon_{r e}=\frac{P_{s, \text { in }}-P_{s, \text { out }}}{P_{s, \text { in }}-P_{a, \text { in }}} \\
\varepsilon_{r e}=79.12+1.21 \times\left(1-\frac{P_{a, \text { in }}}{P_{s, \text { in }}}\right)+4.37 \times \frac{m_{a}}{m_{L}}
\end{gathered}
$$

Where $\mathrm{P}_{\mathrm{s}}$ and $\mathrm{P}_{\mathrm{a}}$ are the solution and air partial pressures respectively; $\mathrm{m}_{\mathrm{a}}$ and $\mathrm{m}_{\mathrm{L}}$ are the air and desiccant mass flow rates respectively.

The heat required for the regeneration process can be taken from a suitable heat source, for example, solar thermal collectors via a thermal fluid (and heat exchangers) to heat the desiccant solution and/or air which are brought into contact in a regenerator. This arrangement can be regarded as an indirect solar utilising regenerator (Fig. 12); however, in alternative arrangements, the regeneration process can be realized directly in the solar collector [117].

\subsubsection{Indirect use of solar energy for regeneration}

The air contacting equipment of the regenerator can be of the same configuration as the dehumidifier, i.e., spray tower, packed tower and falling film column (as discussed in section 2.3); however, the processes occurring within them are in reverse. The membrane based air contacts have also been considered for the regenerator [118]. 


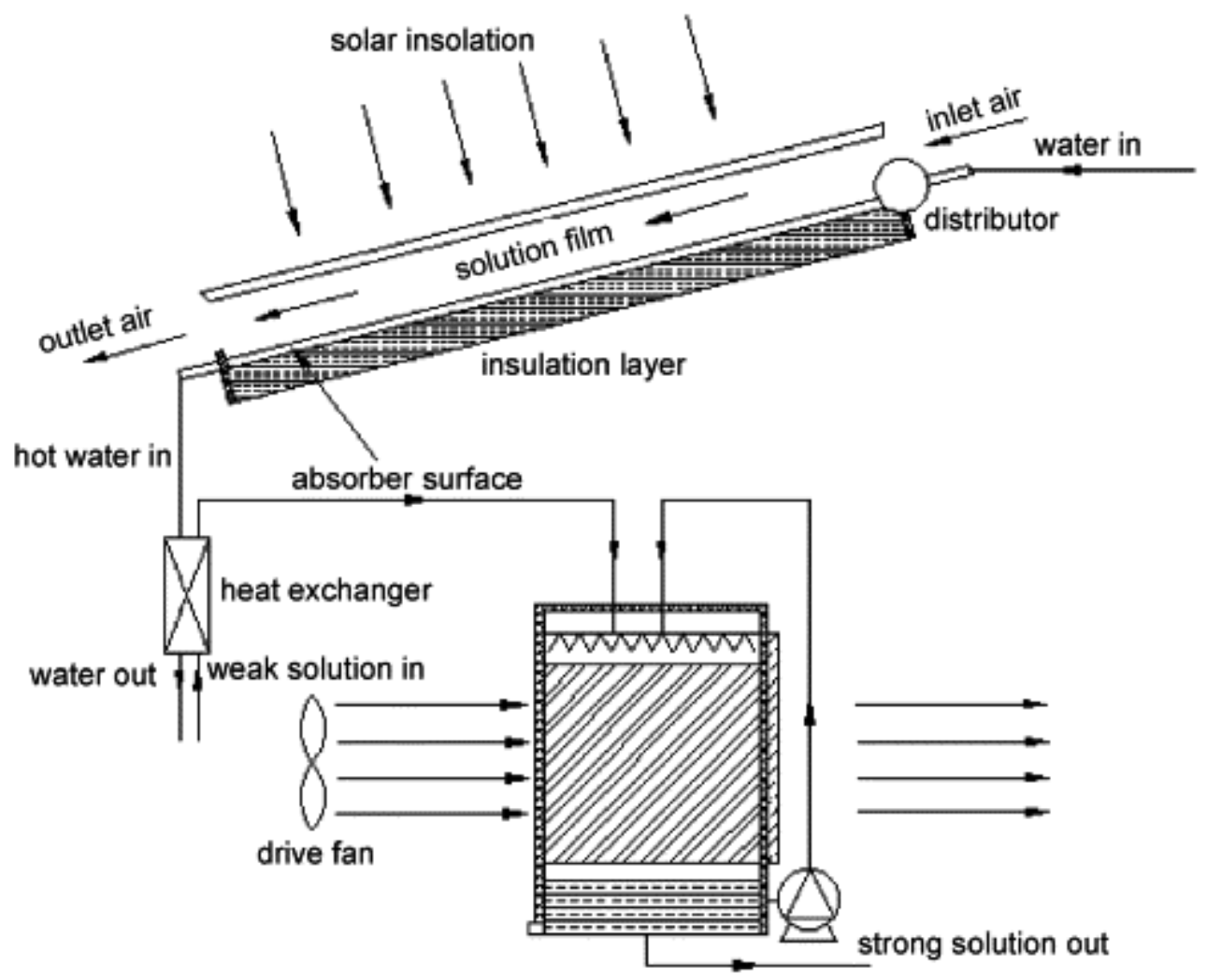

Fig. 12: Schematic of indirect solar energy utilization for regeneration [115]

The packed regenerator has been widely investigated because it offers large contact area for heat and mass transfer [119]. Longo and Gasparella [120] carried out an experimental analysis of lithium bromide desiccant regeneration in packed columns. Their results showed that the desiccant regeneration required temperature levels of about $50^{\circ} \mathrm{C}$; and the regeneration performance of the random packed column showed $20-25 \%$ higher than structured packed column, whereas the structured column showed air side pressure drop 65-75\% lower. A study by Elsarrag [121] on TEG regeneration in the structured packed column, suggested that the desiccant regeneration requires a higher solution temperature in humid climates compared to dry climates.

In typically packed regenerators, heat and mass transfer happen only between the air and desiccant. There is no additional heat transferred into the regenerator. Thus, the desiccant temperature and consequently the mass transfer could deteriorate in the regenerator. Internally heated regeneration (just like internally cooled dehumidifier) could be an alternative to solve this issue $[122,123]$. The internal heating can easily be implemented in spray towers and falling film regenerators with the aid of coils and plates. 


\subsubsection{Direct Open or Closed types}

Unlike the indirect heat regenerator systems, the direct variant does not require separate regenerator equipment, as the desiccant solution is being regenerated directly in the solar collector [124]. This solar collector regenerator arrangement can be of an open or a closed type.

The open-type regenerator is quite a simple configuration; consisting basically a distributor, a tilted blackened surface, and an insulating layer underneath (Fig. 13). On operation, the weak desiccant solution is distributed and flows over the tilted surface, where it gets exposed to ambient air, as it is open to the atmosphere. And mass transfer from the solution to the air occurs, since the vapour pressure of the air is lower than that of the solution.

Being open to the atmosphere, the system can easily be affected by adverse weather conditions and dust contamination; and is also prone to heat loss from the solution to the ambient, which will adversely reduce the regeneration temperature.

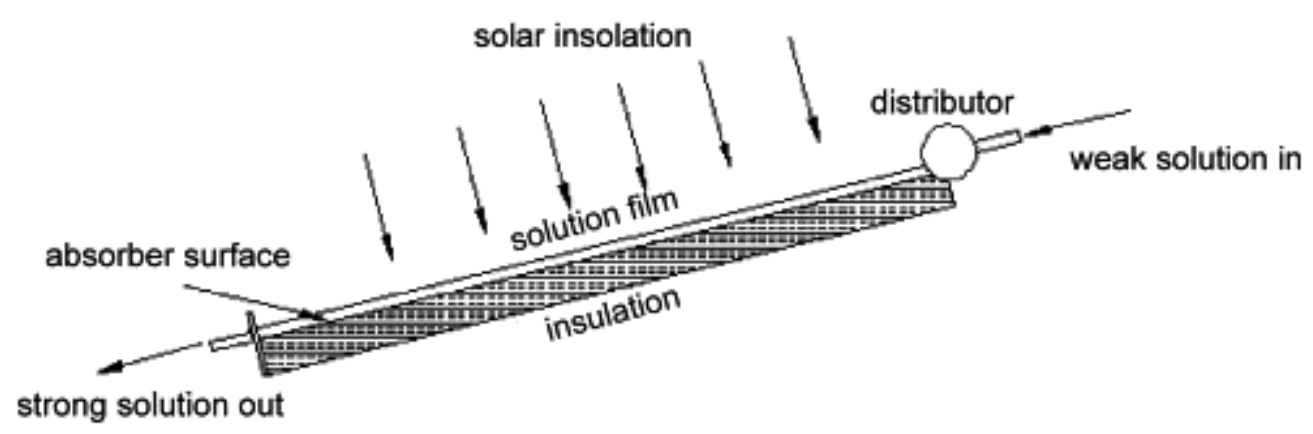

Fig. 13: Schematic of open-type solar regenerator [115]

\subsubsection{Closed-type}

The closed-type regenerator can take the form of simply providing a transparent glazing cover for the aforementioned open-type variant (Fig. 14). The configuration is similar to that of a solar still if both ends of the glazing are sealed. The solar radiation passes through the glass to the solution film flowing over the inclined collector surface; then upon evaporation, the water vapour released from the solution rises to the underside of the glass, where it condenses and is tapped off. 


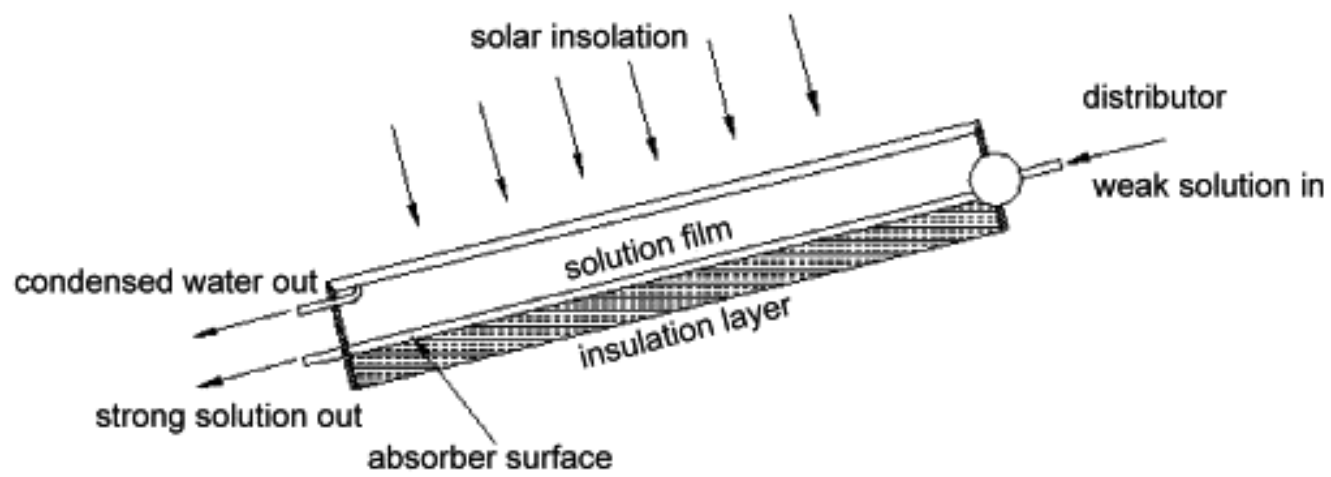

Fig. 14 Schematic of a closed-type solar regenerator [115]

Although the closed-type arrangement may protect against the adverse surrounding atmospheric conditions, and also reduce the heat loss to the ambient; if the basic arrangement lacks ventilation, this will inadvertently lower the driving force for the regeneration process, which is the vapour pressure difference between the solution film and the contained air, because the condensation of vapour underneath the glazing will consequently lead to increase in the vapour pressure of the contained air [115]. However, experimental studies [76] have also reported that the performance can be significantly enhanced if a means of cooling is provided for the glass cover.

\subsubsection{Solar collector regenerator with natural convection and forced convection}

The arrangement of the closed-type solar collector can be subjected to natural or forced convection if the ends of the glazing are open for ventilation [125]. For the natural convection type, the performance can be at the mercy of random wind flow direction. However, studies [126] have indicated that the water evaporation rate can be relatively higher in comparison to the open-type because the reduction in the heat losses can increase the solutions temperature and vapour pressure sufficiently to overcome the associated reduction in the mass-transfer coefficient. Nevertheless, McCormick et al. [127] have reported that there exists an optimal glazing height, beyond which the system performance becomes similar to that of the open-type variant. An experimental study by Yang and Wang [128] found an optimal glazing height as $0.07 \mathrm{~m}$.

On the other hand, for the forced convection type, a continuous flow of air is supplied through the glazing ends. Studies have reported the forced flow configuration to be relatively more effective in comparison to the natural flow variant [129]. Ji and wood [130] indicated that increasing air flow rate could improve performance. However, an experimental study by Kabeel [131] on forced cross-flow also reported similar improvement in performance relative to natural flow. Evaporation rate increases strongly with an increase in air flow rate. However, the evaporation decreases beyond a certain high flow rate. The phenomenon was attributed to the fact that though the increasing air flow rate enhances 
the mass transfer coefficient, excessive flow velocity adversely results in a decrease in the regenerator temperature, and consequently a decrease in the vapour pressure, which may ultimately result in a decrease in performance. This phenomenon has also been reported for parallel flow configuration $[132,133]$.

Elsarrag [134] developed a novel hybrid solar regeneration and studied the influence of varying air flow rate, inlet desiccant temperature, as well as desiccant concentration and inlet air humidity on the evaporation rate. Moreover, he reported the optimum desiccant-to-air flow ratio to maximise evaporation rate, see Fig. 15

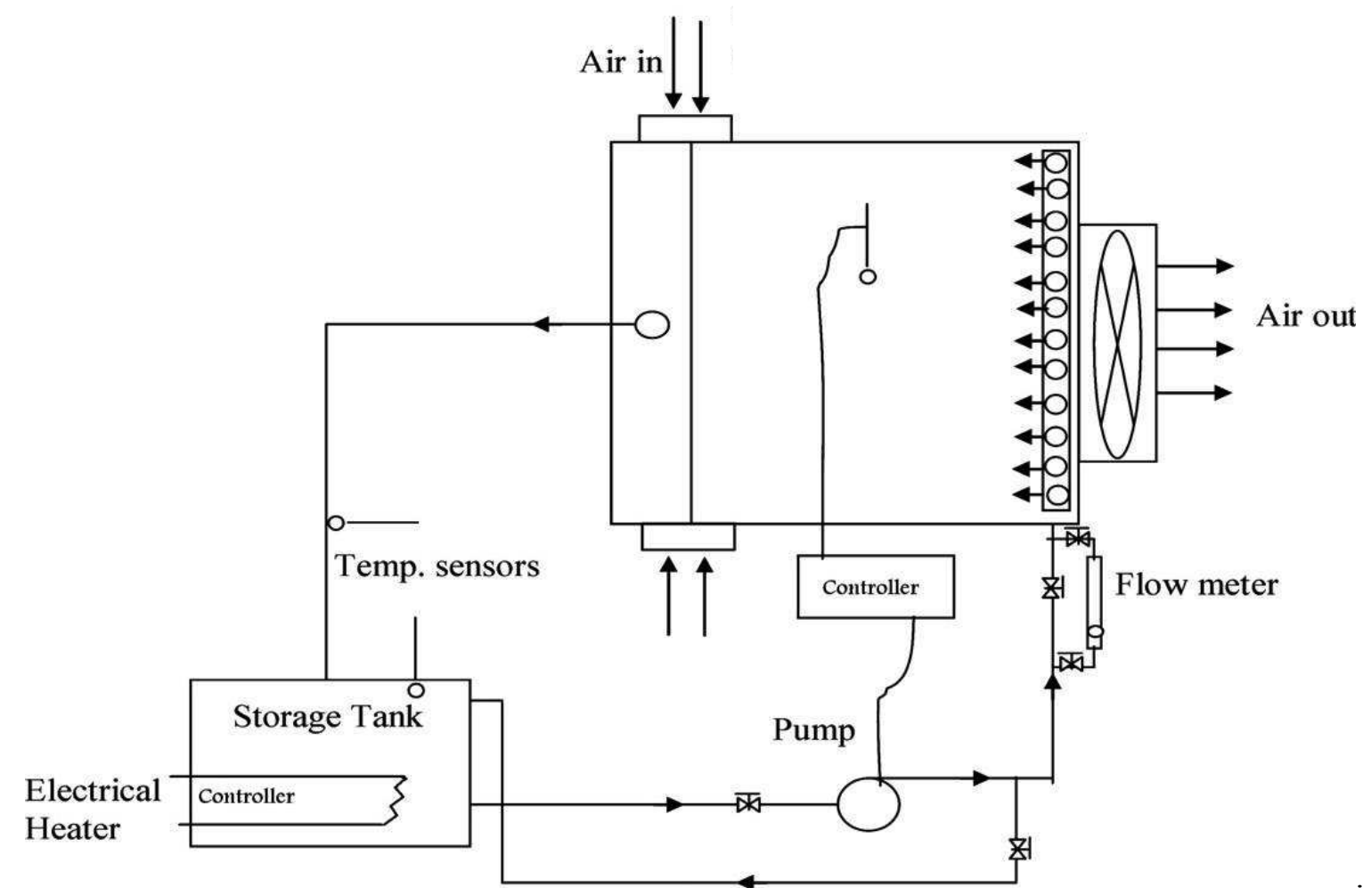

Fig. 15 Schematic of the hybrid solar regenerator [134]

\subsection{Discussion of liquid desiccant cooling systems}

Liquid desiccant cooling systems are especially suitable for solar energy applications since the liquid desiccant can be regenerated at temperatures below $80^{\circ} \mathrm{C}$. The solar energy can be collected and indirectly utilised to re-concentrate weak desiccant solution in air contacting regenerator equipment. On the other hand, direct solar collector regenerators obviate the need for separate regenerator equipment, as the regeneration is directly carried out in the solar collector itself. 
Given the intermittent nature of solar energy, energy storage is essential to provide continuous or extended operation of the liquid desiccant cooling system. Researchers [135, 136] have proposed storage of the concentrated and diluted desiccant solutions, to provide for extended air dehumidification and cooling.

With respect to dehumidification and energy storage, the mass flow ratio $\left(M R=\dot{m}_{\text {air }} / \dot{m}_{\text {sol }}\right)$ of air to desiccant the solution is an important factor for absorber efficiency and system capacity. Previous studies on dehumidifier performance indicated that smaller $M R$ generally results in better performance [20]. On the contrary, Kessling et.al [33] pointed out that storage capacity increases with higher $M R$. As such air-to-solution flow ratios in the liquid desiccant system needs to be adjusted to the thermodynamical requirements for both air dehumidification and energy storage to be possible at the same time [137]. Laevemann and Sizmann [138] showed that salt solution desiccants are well suited as storage material for dehumidification and that storage capacities up to $1000 \mathrm{MJ} / \mathrm{m}^{3}$ are achievable.

From the preceding, it can be seen that direct solar collector regenerators and energy storage capability are both desirable features that are been sought in advancing liquid desiccant cooling systems; therefore it can be deduced that an arrangement that inherently combines these two features would present a promising field of study. And given that salt solution desiccants are well suited as a storage material for dehumidification, it can be proposed that the salt desiccant solution reservoir can be fashioned in the form of a solar pond to collect directly and store the solar energy, whilst providing the needed desiccant for dehumidification and cooling.

In a nutshell, in conventional practice, the typical solar pond (like other conventional solar collectors such as flat plate, evacuated tube, parabolic trough) can be employed to capture solar energy that can be delivered via heat exchangers to re-concentrate weak desiccant solution in the regenerator equipment. However, as an alternative with a minimal number of components, this paper is recommending a potential arrangement where the solar pond is itself the regenerator, thus having the combined features of the solar collector, energy storage and desiccant regeneration. Nevertheless, the proposed concept will require further research work in investigating the practical realization of the concept. The next section will review the state of the art in solar pond technology. 


\section{Solar Ponds}

In this section, we review solar ponds with a focus on their potential application in liquid desiccant cooling. Back in 1902, Kalecsinsky observed a natural salt lake in Transylvania in East Europe and published his report on a natural solar lake $[139,140]$. It was noted that the water had a temperature of $70^{\circ} \mathrm{C}$ at a depth of $1.32 \mathrm{~m}$ during summer and a minimum temperature of $26^{\circ} \mathrm{C}$. The bottom salinity was near $26 \%$ of $\mathrm{NaCl}$. A similar lake was reported in Washington USA by Anderson [141,142], and a temperature of $50^{\circ} \mathrm{C}$ was observed at a depth of $2 \mathrm{~m}$ during summer. In 1948, Bloch [143] proposed the salinity gradient solar pond (SGSP) as a solar energy collector and a thermal storage device. These observations encouraged the theoretical and experimental studies aimed at designing and constructing artificial solar ponds to collect and store solar thermal energy. Tabor, Weinberger and Tabor and Matz did extensive pioneering work on SGSP [144-146]. Besides the proposed use in liquid desiccant cooling, solar ponds can be used in various of applications such as heating and cooling of buildings, power production, desalination, power productions and many [147].

A solar pond is considered to be a basin of water with a gradient concentration of dissolved salts that collects solar energy and stores it as thermal energy within its depth, so it acts as a collector and a storage device at the same time. When the sun's rays fall on a pond, the water molecules heat up and the temperature increases towards the bottom of the pond. This would normally cause the water to rise; however, this is avoided in salt gradient solar ponds prevent as dissolved salt in the bottom layer of the makes the water too dense to rise to the surface. Therefore, solar thermal energy accumulates at the bottom of the pond, causing the temperature to rise up to $100^{\circ} \mathrm{C}$ or even more [148]. Such high temperatures can provide a heat source which is accessed by withdrawing brine or using a heat exchanger [149]. The various types of solar ponds fall into two main categories: non-convecting and convecting solar ponds [150].

\subsection{Non-convecting Solar Ponds}

This type of pond inhibits the heat loss due to convection by stopping the currents of convection from occurring within the fluid. The name comes from the non-convecting zone between the upper convective zone and the lower zone [151]. Non-convecting ponds consist of three salt water layers, where the highest salinity concentration is in the bottom layer, and it is divided into four sub-types: Salinity Gradient Solar Ponds, Membrane Solar Ponds, Viscosity Stabilized Ponds, Partitioned Solar Ponds and Saturated Solar Ponds [152]. 


\subsubsection{Salinity Gradient Solar Ponds (SGSP):}

The SGSP consists of three different zones or layers. The first is the Upper Convective Zone (UCZ) or the Surface Zone, which has the least salinity. The second layer is the Non- Convective Zone (NCZ) or the Gradient zone, with a graduate increase of density. The third layer is the Lower Convective Zone (LCZ), which also referred as the Storage Zone with a uniform density and the highest concentration of salinity as shown in Fig. 16.

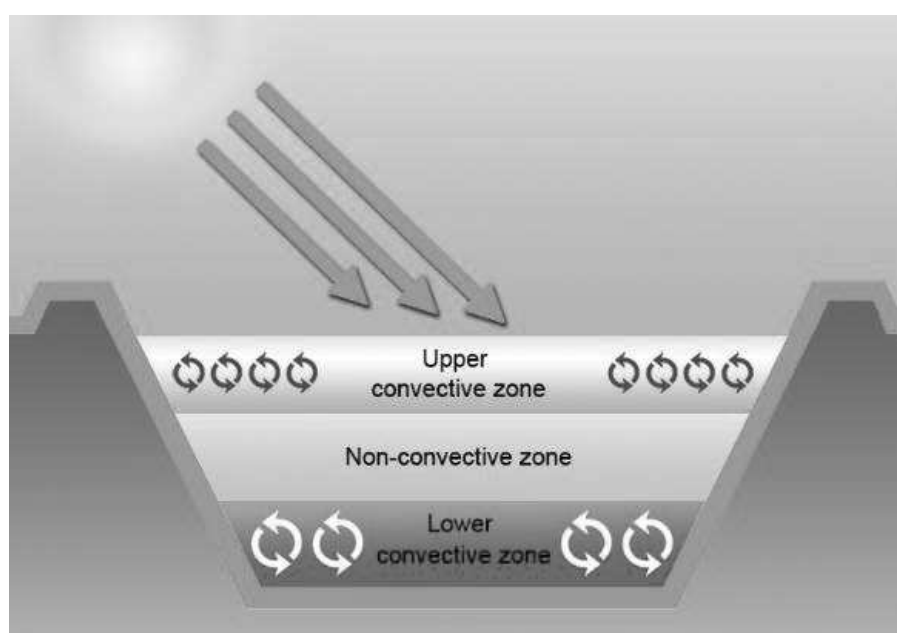

Figure 16: Schematic representation of a salinity-gradient solar pond

SGSP is a device that collects solar energy using salt solution with different densities to inhabit the natural convection and stores it as thermal energy [160]. The SGSP consists of three layers; the Upper Convecting Zone (UCZ), the non-convecting zone (NCZ) and the Lower Convecting Zone (LCZ) as shown in Fig. 17.

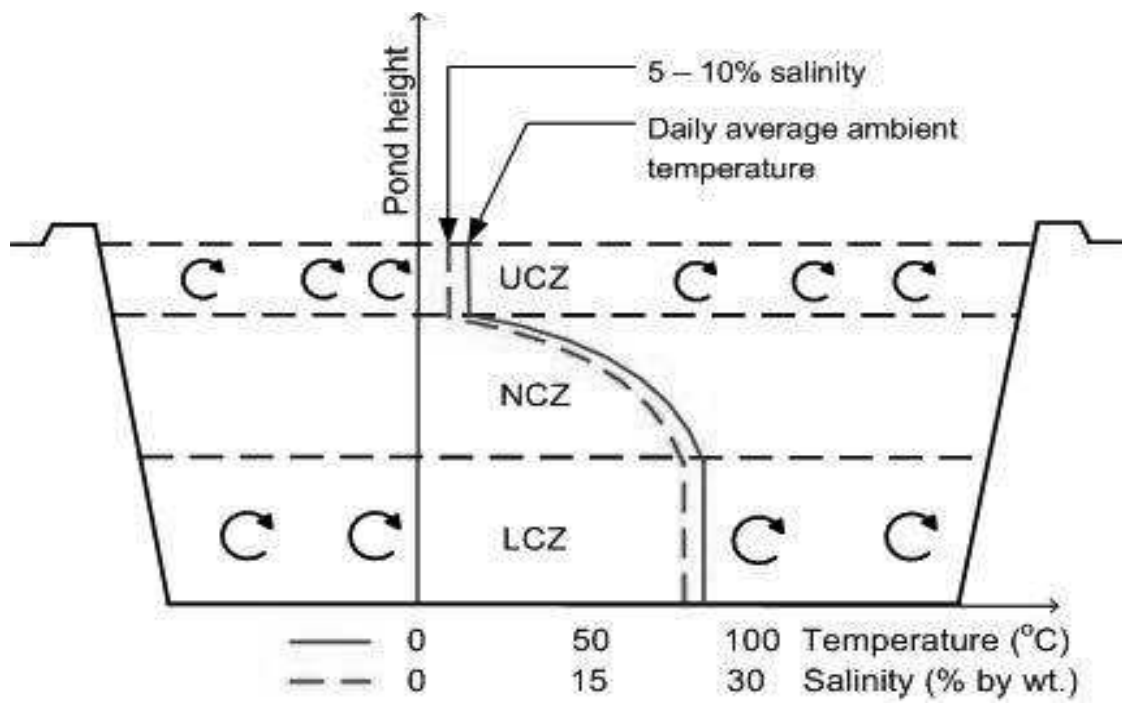

Fig. 17: Schematic showing the different salinity gradient zones 


\subsubsection{The Upper Convective Zone:}

This zone consists of fresh or low salinity water that acts as a zone for solar absorption and transmission. The water temperature within this zone is close to ambient temperature. Usually, the depth or thickness of this layer is between 0.2-0.5 meters, and it is better to keep this layer as shallow as possible, typically at 0.3 meters. UCZ usually influenced by wind agitation and convective mixing.

\subsubsection{The Non-Convective Zone:}

This zone is located in the middle of the solar pond and separates the UCZ and the LCZ. This layer is much thicker than the UCZ and it is recommended to be between 0.8-1.5 meters this with an optimum thickness if 1 meter. This layer is not homogeneous because the temperature and the salinity increase with depth as shown in Figure 16. Therefore, NCZ provides stability to the pond at which it prevents any gravitational over turn also it inhabits the heat loss due to convection.

\subsubsection{The Lower Convective Zone:}

This zone is a homogenous layer that has the highest salt concentration and the highest temperature, and it is constant within this layer; this layer stores the solar energy as thermal energy and it can be withdrawn in and out of the pond by extracting the hot brine. The depth of this layer can be as the depth of NCZ, but it is typical to be 1 meter deep with an option to be more.

\subsubsection{Membrane Solar Ponds (MS):}

Membrane solar ponds are similar to the SGSP. In membrane solar ponds, however, a thin transparent membrane is installed to separate the zones of the pond and to suppress the convection; although the heat is exchanged in a similar manner in SGSP. Membrane Solar Ponds have horizontal sheets, vertical tubes and vertical sheets [153].

\subsubsection{Viscosity Stabilized Solar Pond (VSSP):}

SGSP can lead to environmental pollution, in the case of a salt leakage. Moreover, the salt gradient layer requires constant maintenance. To overcome such difficulties, Shaffer [154] proposed a hybrid solar pond that contains a transparent polymer gel to act as a non-convective layer or zone. The polymers used in such pond should have a high transmittance for solar radiation, high efficiency of the chosen thickness and should be able to operate at temperatures up to $60^{\circ} \mathrm{C}$. Starch, Gelatin and Arabic gum can be suitable materials to use in viscosity stabilized solar ponds [155]. 


\subsubsection{Partitioned Solar Pond (PSP):}

This solar pond has a similar principle as the Membrane Solar Pond [155]. In this type, two transparent partitions are installed. This idea occurred when Tabor [156] has noticed some problems during the operations of a solar pond. Bacterial and algae growth was a common problem facing most of the solar ponds. Moreover, the accumulation of dirt and dust in the pond caused a decrease in the transparency of the pond. Hence, less solar radiation absorbed. More problems such as evaporation have an effect on the salt concentration, making the top layer with high concentrations of salt [157]. In order to overcome these problems, two transparent partitions are installed one on top or few centimeters blow the surface of the pond, and the other at a depth of $1-2 \mathrm{~m}$. There are some disadvantages associated with the thin layer of water above the top partition. The disadvantages include evaporative cooling and reflectivity increase due to wave's movements, especially in windy sites. However, on the other hand, the reflective losses are decreased due to the lower index of refraction of water than plastics. An added advantage of installing partitions would be that the lower partition separates the insulating layer from the convective layer from the convective layer. This improves the stability of the solar pond and eases the heat extraction [139, 157].

\subsubsection{Saturated Solar Ponds (STSP):}

The principle of a saturated solar pond is to have salt whose solubility increases with temperature, saturating the pond at all levels. This pond requires less maintenance, due to its ability to self-sustain the salt gradient and its stability. STSP are best used for short-term energy storage due to the rapid rise in temperature of the pond water [158].

\subsection{Convecting Solar Ponds:}

Convecting solar ponds are quite different to non-convecting solar ponds in that they consist of one layer of homogenous fluid and covered with a transparent cover to inhabit heat loss due to evaporation and convection/conduction. Moreover, the cover can protect the solar pond from dust and any falling impurities. Convecting solar ponds were identified according to its basis of operational modes, however, Kreider and Keith categorized these ponds according to depth [149]. On the other hand, some researchers considered all convective solar ponds to be shallow solar ponds [140] whereas other researchers considered shallow solar ponds to be those having depths between 4 and $15 \mathrm{~cm}$ [155]. Shallow solar ponds are not a new concept. In early twentieth century, Willsie and Boyle used the idea to produce shaft power [159]. They approached different designs of the solar pond and one of the solar ponds consisted of a wooden tank with a tar paper lining and covered by a window made of 
glass while the pond was insulated with hay. The water depth in that pond was $7.5 \mathrm{~cm}$. More designs had asphalt and sand as insulation materials.

\subsection{Design of Solar Ponds:}

\subsubsection{General considerations}

The solar pond designer needs to consider the type of fluid to be eventually heated (e.g. liquid or air), the target temperature and heating amount to be delivered. The storage temperature should be higher than the delivered temperature to account for losses. The designer also needs to consider the availability of fresh and saline water, land, contractors and labourers for construction. Local contractors and labour are preferred.

\subsubsection{Site Selection}

An ideal site to constructs a solar pond should would the following characteristic [161]. It is recommended to select a site with a free draining soil. A dry soil will and soil with good cohesion for forming stable walls.

- free draining and dry and solid soil

- adjacent free or low-cost saline water

- $\quad$ easy access to water supply for the pond.

- high incident solar radiation to achieve a good thermal performance.

- low wind speeds to minimize the wave- induced mixing and the depth of the top mixed zone.

- low amount of wind-borne debris to maintain cleanliness of the pond.

- flat land to minimize earth moving requirements.

- a method to withdraw heat readily.

- a stationary or deep groundwater to minimize heat loss on the ground.

\subsubsection{Thermal Output and sizing}

The thermal performance of solar pond depends on the absorption of solar radiation within the layers of the pond. Therefore, the water in the pond should always be clear as much as possible in order to get the maximum amount of solar radiation within the storage zone. The more radiation that reaches there, the higher efficiency of energy and operating temperatures of the pond will be achieved [159]. Usually, a solar pond is around 3 meters deep, and a storage zone with 1-meter thickness can receive between $20-25 \%$ of radiation. Taking into consideration the heat losses to the surrounding ground, a pond might get around $15-20 \%$ of the radiation that can be extracted into the desired application. 
Usually, the heat delivery would be around 40 to 50 degrees above the average daily temperature of the location $[161,162]$.

To estimate the pond surface area required to achieve the desired thermal load, the following should be done:

I. look up the annual solar energy incident on a square meter of horizontal surface at the location of the pond.

II. calculate the horizontal surface area on which the incoming solar radiation over a year is equal to the annual load desired to be supplied.

III. Multiply this surface area by a factor of 5 to 10 to estimate the surface area of the solar pond. other factors that can impact the actual design of a solar pond is the brine used and the water quality and transparency.

\subsubsection{Site preparation, excavation and lining}

When constructing a pond, it is better to choose a land that is flat as possible. Moreover, to minimize the heat losses to the ground, it is recommended that underground water is 5 meters or more below the natural ground surface. If this option is not available, then using insulation at the bottom of the pond is required.

In large solar ponds that can be 1000 meter square and above, it is recommended to construct the pond by establishing the walls using the soil excavated from the periphery of the pond. The bottom of the pond will thus be below the ground level. Such arrangement can provide the head required for gravity feeding of the surface water from the solar pond to the adjacent evaporation pond.

Although unlined ponds can operate well, in many locations pond lining is necessary to prevent any leakages of brine and heat. When choosing a liner material, a material with high resistance to heat and ultraviolet radiation should be considered. The material should also be chemically stable and can withstand the mechanical strain of the solar pond. Usually, failure of liners is the most faced problems while operating a pond [162].

\subsubsection{Source of Salt:}

The commonly used salts in SGSP are sodium chlorides and bitterns. Bitterns usually consist of magnesium-potassium solutions as a result of salt production and desalination of seawater. Therefore, it is economically and environmentally beneficial to use sea water bitterns instead of sodium chloride. It is also important to recycle the salt extracted from the pond by surface washing. This step would minimize the cost of operating the pond and will minimize the burden on the environment. The salt 
solution flushed from the surface of the solar pond can be collected in an adjacent evaporation pond and there concentrated for later injection back into the storage or gradient zones of the pond. An evaporation pond needs to be at least equal or more than the total area of the solar pond. Figure 18 shows a solar pond with an evaporation pond.

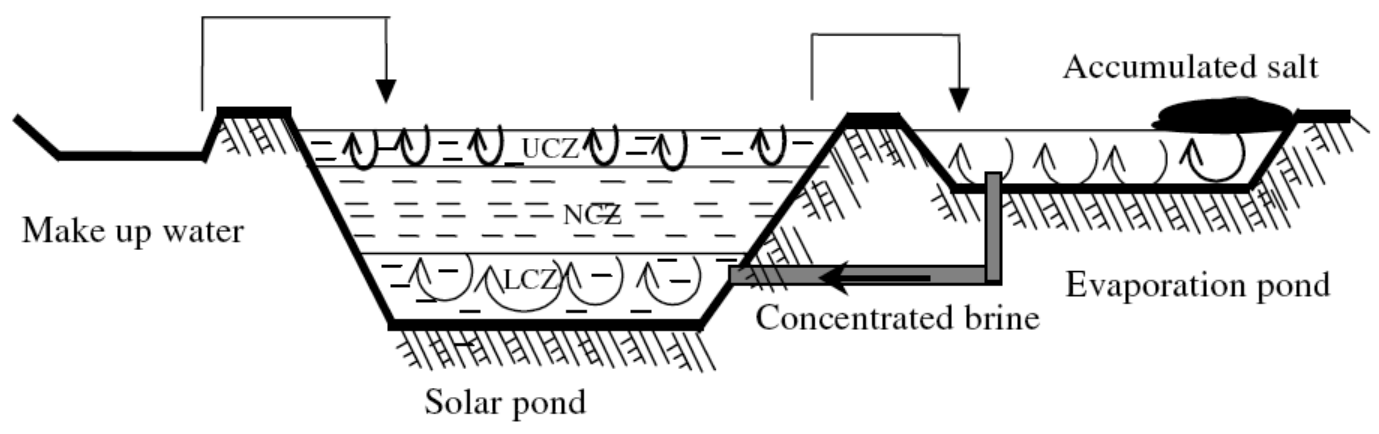

Fig. 18: A solar pond with an evaporation pond

Dissolved salts and water are the main requirements to establish the SGSP; it only needs highly concentrated brines and low salinity brine or fresh water. Brines used in ponds effect the overall cost of the solar ponds depending on the physical and chemical properties [148, 155].

\subsubsection{Source of water}

A source of fresh water or low salinity water hence, less than $50,000 \mathrm{ppm}$ salt concentration, should be available. The amount of fresh water required to establish a pond is measure by volume from the surface of the pond to the middle of the gradient layer. The amount of water needed to maintain the gradient depends on the losses due to evaporation and the flow rate of the overflow system removing the surface flushing water that contains the salt that has diffused upwards.

The rate of adding water to the surface zone must not exceed the rate of removal through the overflow by the rate of evaporation $[161,162]$.

\subsection{Examples of solar ponds}

In the past decades, many solar ponds were constructed to be used in heat or power supply. Some of the main projects are reviewed here according to the country.

Lots of efforts and studies into deploying solar ponds technology, therefore the first commercial scale solar pond in the world was constructed in Ein Boqek in December 1979 [163]. The power units that were constructed near the dead sea are listed below [164]: 
- A solar pond in Ein Bokek at the shore of the Dead Sea. The pond had a surface area of $7500 \mathrm{~m}^{2}$ and a depth of $2.6 \mathrm{~m}$ and the maximum temperature achieved was $92^{\circ} \mathrm{C}$. It provided between $150-170 \mathrm{~kW}$ with efficiency between $15-19.4 \%$.

- A solar pond in Bet Havara with a surface area of $25000 \mathrm{~m}^{2}$ to supply 5MW of power.

- A Solar pond in Yavne with a surface area of $1500 \mathrm{~m}^{2}$ providing $6 \mathrm{~kW}$ of power.

- A Solar Pond at the Dead Sea Potash Works with a surface area of $1100 \mathrm{~m}^{2}$ that has a maximum temperature of $103^{\circ} \mathrm{C}$ and had an efficiency of $15 \%$.

\begin{abstract}
Australia started deploying Solar Ponds for the production of salt. Therefore, a project was set up at Pyramid Hill Salt Pty Ltd with collaboration with RMIT University. The application of this solar pond was for industrial process heating and drying process in commercial salt production.
\end{abstract}

Major Solar Ponds in Australia have included [164-166]:

- Pyramid Hill Solar Pond with a surface area of $3000 \mathrm{~m}^{2}$ providing up to $60 \mathrm{~kW}$ of heat for salt production. HDPE [Nylex Millennium] was used as a liner for this pond, and it had a thickness of $1 \mathrm{~mm}$.

- Alice Springs Solar Pond with an area of between 1600-2000 $\mathrm{m}^{2}$. The pond had a depth of 2.3 $\mathrm{m}$ and the hot brine obtained from the storage zone was between $82-90^{\circ} \mathrm{C}$. The pond operated at an efficiency of $12-15 \%$ to deliver $20 \mathrm{~kW}$.

Margherita Di Savoia Solar Pond was constructed in the southern of Italy. The pond had a surface area of $25000 \mathrm{~m}^{2}$ with a depth of 4 meters and it supplied $500 \mathrm{~kW}$ of process heat. HD PVC and HDPE pipes were used for bitterns or sea water. On other hand, insulated fiberglass pipes were used for extracting hot brine from the storage zone. Polypropylene lining were used to line the pond and it was $2.5 \mathrm{~mm}$ thick [167].

North America applied lots of research on solar ponds technology since 1974. Some of the solar ponds constructed were the following $[157,164]$ :

- Ohio State University built a $200 \mathrm{~m}^{2}$ solar pond for energy storage. The depth of the pond was 2.5 m and maximum temperature achieved was $66^{\circ} \mathrm{C}$.

- Again in Wooster, Ohio, a pond with a surface area of $156 \mathrm{~m}^{2}$ and a depth of $3 \mathrm{~m}$. The aim for this solar pond was to provide heat for greenhouses. It was noted that the pond provided around 20GJ in less than two months of its operation.

- The University of New Mexico constructed a $175 \mathrm{~m}^{2}$ solar pond to use it for heat extraction. The maximum temperature achieved was $109^{\circ} \mathrm{C}$ at a depth of 2.5 meters. The energy of 63GJ was extracted in a period of 12 months. 
- Miamisburg, Ohio used a $2020 \mathrm{~m}^{2}$ solar pond for swimming pool heating. The pond had a depth of 3.5 meters and achieved a maximum temperature of $66^{\circ} \mathrm{C}$ with an efficiency of $15 \%$.

- One of the most popular ponds was designed and operated by University of Texas, El Paso solar pond. El Paso provided between 100 to $120 \mathrm{~kW}$ of power from a surface area around $3000 \mathrm{~m}^{2}$. The depth of the pond was 3.2 meters and the maximum temperature achieved in the storage zone was around $93{ }^{\circ} \mathrm{C}$. However, this pond faced lots of operating difficulties due to liner failures.

- A $700 \mathrm{~m}^{2}$ pond in Montreal, Canada was developed to preheat air injected into an industrial air dryer. The pond was only 2 meters deep and provided around 360 GJ of power annually. The maximum temperature recorded from this pond was $70^{\circ} \mathrm{C}$.

Bhuj Solar pond is a $6000 \mathrm{~m}^{2}$ pond used to provide heat for Dairy industry at which it heated up around 8000 liters a day in India. The heat was extracted at a depth of 3 meters and a temperature of $70^{\circ} \mathrm{C}$. The pond was lined with an inexpensive lining scheme made of alternated layers of clay and LDPE films. However, this solar pond has faced many problems regarding the linning [167].

Al-Marafie constructed a $1700 \mathrm{~m}^{2}$ area solar pond of $3.5 \mathrm{~m}$ depth, with 1:1 slope, at Kuwait Institute of Scientific Research, Kuwait, where severe weather conditions exist, with the aim of producing 25 $\mathrm{m}^{3}$ of fresh water using Multistage Flash Desalination unit. A maximum storage zone temperature of $58^{\circ} \mathrm{C}$ could be achieved. The pond lining was achieved with PVC sheets of 500 micron thickness placed under XR-5 liner [168].

\section{Conclusion}

Liquid desiccant cooling systems are attractive in providing space cooling at low energy requirement. The desiccant solution is employed to remove moisture from process air (in a dehumidifier equipment) before been sensibly cooled (in an evaporative cooler), whilst the resulting diluted solution is regenerated for reuse. A review of the various components showed that: the packed tower dehumidifier is quite popular; its air-to-solution flow ratio is generally below 0.5 for optimum dehumidification effectiveness. Of the desiccant solutions, though $\mathrm{LiCl}$ and TEG are widely studied, $\mathrm{MgCl}_{2}$ is more cost effective; here solution concentration below $35 \%$ is required to avoid crystallization issues. On the other hand, for the evaporative coolers, the DPEC was found to be the most efficient (substantially lower temperatures can be obtained). The liquid desiccant can be regenerated at temperatures below $80^{\circ} \mathrm{C}$ making it well suited to low-grade solar energy applications. 
The regenerator can be of the same type of equipment as the dehumidifier (for example packed bed, spray tower or falling film), in which case, the required thermal energy for the regeneration process can be indirectly sourced from conventional solar thermal collectors via heat exchangers. However, in alternative arrangements, the desiccant solution can be directly regenerated in an appropriate solar collector system, thus obviating the need for separate regenerator equipment.

The regenerated desiccant solution can potentially be stored to provide a high energy storage capacity for extended air dehumidification and cooling; however, this will require sufficiently large solar collector size. Of the solar collector types, a solar pond is a well-suited option for this purpose of large scale solar collection and thermal storage. The solar pond option is worthy of further research and development. The schematic diagram of the future experimental work with all components is presented which consists of Salt Gradient Solar Pond (SGSP) and Indirect-Direct Evaporative Cooler.

\section{Acknowledgment}

The authors would like to acknowledge the support provided by Qatar National Research Foundation for this research. The study was funded through Qatar National Research Foundation grant NPRP No. 7 - 332 - 2 - 138 


\section{References}

[1] Gandhidasan P. Analysis of a solar space cooling system using liquid desiccants. Journal of Energy Resources Technology. 1990;112:246-50.

[2] ASHRAE Standard 55-2013. Thermal Environmental Conditions for Human Occupancy: American Society of Heating, Refrigerating, and Air conditioning Engineers, Inc. Atlanta, USA; 2013.

[3] Jiang Y, Ge T, Wang R. Performance simulation of a joint solid desiccant heat pump and variable refrigerant flow air conditioning system in EnergyPlus. Energy and Buildings. 2013;65:220-30.

[4] Cheng Q, Zhang X. Review of solar regeneration methods for liquid desiccant air-conditioning system. Energy and Buildings. 2013;67:426-33.

[5] Wrobel J, Morgenstern P, Schmitz G. Modeling and experimental validation of the desiccant wheel in a hybrid desiccant air conditioning system. Applied Thermal Engineering. 2013;51:1082-91. [6] Burns P, Mitchell J, Beckman W. Hybrid desiccant cooling systems in supermarket applications. ASHRAE transactions. 1985;91:457-68.

[7] Luo Y, Wang M, Yang H, Lu L, Peng J. Experimental study of the film thickness in the dehumidifier of a liquid desiccant air conditioning system. Energy. 2015;84:239-46.

[8] Gandhidasan P, Mohandes MA. Artificial neural network analysis of liquid desiccant dehumidification system. Energy. 2011;36:1180-6.

[9] Daou K, Wang RZ, Xia ZZ. Desiccant cooling air conditioning: a review. Renewable and Sustainable Energy Reviews. 2006;10:55-77.

[10] Saghafifar M, Gadalla M. Innovative inlet air cooling technology for gas turbine power plants using integrated solid desiccant and Maisotsenko cooler. Energy. 2015;87:663-77.

[11] Koronaki IP, Rogdakis E, Kakatsiou T. Thermodynamic analysis of an open cycle solid desiccant cooling system using Artificial Neural Network. Energy Conversion and Management. 2012;60:15260 .

[12] Hürdoğan E, Büyükalaca O, Tolga Balta M, Hepbasli A, Y1lmaz T. Experimental exergoeconomic assessment of a desiccant cooling system. Energy Conversion and Management. 2013;69:9-16.

[13] Qi R, Lu L, Huang Y. Energy performance of solar-assisted liquid desiccant air-conditioning system for commercial building in main climate zones. Energy Conversion and Management. 2014;88:749-57.

[14] La D, Dai YJ, Li Y, Wang RZ, Ge TS. Technical development of rotary desiccant dehumidification and air conditioning: A review. Renewable and Sustainable Energy Reviews. 2010;14:130-47.

[15] Jain S, Bansal PK. Performance analysis of liquid desiccant dehumidification systems. International Journal of Refrigeration. 2007;30:861-72.

[16] Lychnos G. Feasibility of a solar powered liquid desiccant cooling system for greenhouse [PhD Thesis]. Birmingham, UK: Aston University; 2010.

[17] Crofoot L, Harrison S. Performance Evaluation of a Liquid Desiccant Solar Air Conditioning System. Energy Procedia. 2012;30:542-50.

[18] Zurigat YH, Abu-Arabi MK, Abdul-Wahab SA. Air dehumidification by triethylene glycol desiccant in a packed column. Energy Conversion and Management. 2004;45:141-55.

[19] Namvar R, Pyra D, Ge G, Simonson CJ, Besant RW. +Transient characteristics of a liquid-to-air membrane energy exchanger (LAMEE) experimental data with correlations. International Journal of Heat and Mass Transfer. 2012;55:6682-94.

[20] Fumo N, Goswami DY. Study of an aqueous lithium chloride desiccant system: air dehumidification and desiccant regeneration. Solar Energy. 2002;72:351-61. 
[21] Dow Chemical Company: A Guide to Glycols. Dow Chemical Company, Midland Michigan, USA, 1992.

[22] Perry RH, Chilton CH. Chemical Engineer's Handbook. 5 ed. New York, USA: McGraw-Hill; 1996.

[23] Dow Chemical Company: Calcium Chloride Handbook. Dow Chemical Company, Midland, Michigan, USA, 1992.

[24] Etras A, Gandhidasan P, Kiris I, Anderson E. Experimental study on the performance of a regeneration tower for various climatic conditions. Solar energy. 1994;53:125-30.

[25] Ahmed A, Abdalla KN. Moisture removal rate in a solar powered liquid desiccant air conditioning system. Proceedings of the Asian Conference on Sustainability, Energy \& the Environment. Osaka, Japan. 2012.

[26] Han Y, Yi LF. Indoor Environment Quality in Modern Life. Advanced Materials Research: Trans Tech Publ; 2013.p. 207-10.

[27] Yiğit A. A numerical study of heat and mass transfer in falling film absorber. International communications in heat and mass transfer. 1999;26:269-78.

[28] Mohammad AT, Mat SB, Sulaiman MY, Sopian K, Al-abidi AA. Historical review of liquid desiccant evaporation cooling technology. Energy and Buildings. 2013;67:22-33.

[29] Rafique MM, Gandhidasan P, Rehman S, Al-Hadhrami LM. A review on desiccant based evaporative cooling systems. Renewable and Sustainable Energy Reviews. 2015;45:145-59.

[30] Kessling W, Laevemann E, Kapfhammer C. Energy storage for desiccant cooling systems component development. Solar Energy. 1998;64:209-21.

[31] Elsarrag E, M. Ali EE, Jain S. Design guidelines and performance study on a structured packed liquid desiccant air-conditioning system. HVAC\&R Research. 2005;11:319-37.

[32] Tu M, Ren C-Q, Zhang L-A, Shao J-W. Simulation and analysis of a novel liquid desiccant airconditioning system. Applied Thermal Engineering. 2009;29:2417-25.

[33] Kessling W, Laevemann E, Peltzer M. Energy storage in open cycle liquid desiccant cooling systems. International Journal of Refrigeration. 1998;21:150-6.

[34] Lazzarin RM, Longo GA, Gasparella A. Theoretical analysis of an open-cycle absorption heating and cooling system. International Journal of Refrigeration. 1996;19:160-7.

[35] Gommed K, Grossman G. Investigation of an improved solar-powered open absorption system for cooling, dehumidification and air conditioning. International Journal of Refrigeration.

2012;35:676-84.

[36] Enteria N, Yoshino H, Mochida A. Review of the advances in open-cycle absorption airconditioning systems. Renewable and Sustainable Energy Reviews. 2013;28:265-89.

[37] Misha S, Mat S, Ruslan MH, Sopian K. Review of solid/liquid desiccant in the drying applications and its regeneration methods. Renewable and Sustainable Energy Reviews.

2012;16:4686-707.

[38] Kumar R, Dhar PL, Jain S. Development of new wire mesh packings for improving the performance of zero carryover spray tower. Energy. 2011;36:1362-74.

[39] Bansal P, Jain S, Moon C. Performance comparison of an adiabatic and an internally cooled structured packed-bed dehumidifier. Applied Thermal Engineering. 2011;31:14-9.

[40] Luo Y, Shao S, Xu H, Tian C, Yang H. Experimental and theoretical research of a fin-tube type internally-cooled liquid desiccant dehumidifier. Applied Energy. 2014;133:127-34.

[41] Zhang T, Liu X, Jiang J, Chang X, Jiang Y. Experimental analysis of an internally-cooled liquid desiccant dehumidifier. Building and Environment. 2013;63:1-10.

[42] Abdul-Wahab SA, Zurigat YH, Abu-Arabi MK. Predictions of moisture removal rate and dehumidification effectiveness for structured liquid desiccant air dehumidifier. Energy. 2004;29:1934. 
[43] Gao WZ, Shi YR, Cheng YP, Sun WZ. Experimental study on partially internally cooled dehumidification in liquid desiccant air conditioning system. Energy and Buildings. 2013;61:202-9. [44] Liu J, Zhang T, Liu X, Jiang J. Experimental analysis of an internally-cooled/heated liquid desiccant dehumidifier/regenerator made of thermally conductive plastic. Energy and Buildings. 2015;99:75-86.

[45] Koronaki IP, Christodoulaki RI, Papaefthimiou VD, Rogdakis ED. Thermodynamic analysis of a counter flow adiabatic dehumidifier with different liquid desiccant materials. Applied Thermal Engineering. 2013;50:361-73.

[46] Rai P, Shukla S. Performance Evaluation of a Desiccant Dehumidifier using Different Desiccants. Distributed Generation and Alternative Energy Journal. 2013;28:53-73.

[47] Chung T-W, Wu H. Dehumidification of air by aqueous triethylene glycol solution in a spray tower. Separation Science and Technology. 1998;33:1213-24.

[48] Chung T-W, Wu H. Comparison between spray towers with and without fin coils for air dehumidification using triethylene glycol solutions and development of the mass-transfer correlations. Industrial \& engineering chemistry research. 2000;39:2076-84.

[49] Gandhidasan P. Prediction of pressure drop in a packed bed dehumidifier operating with liquid desiccant. Applied Thermal Engineering. 2002;22:1117-27.

[50] Al-Farayedhi AA, Gandhidasan P, Al-Mutairi MA. Evaluation of heat and mass transfer coefficients in a gauze-type structured packing air dehumidifier operating with liquid desiccant. International Journal of Refrigeration. 2002;25:330-9.

[51] Abdul-Wahab SA, Abu-Arabi MK, Zurigat YH. Effect of structured packing density on performance of air dehumidifier. Energy Conversion and Management. 2004;45:2539-52.

[52] Elsarrag E. Moisture removal rate for air dehumidification by triethylene glycol in a structured packed column. Energy conversion and management. 2007;48:327-32.

[53] Elsarrag E. Dehumidification of air by chemical liquid desiccant in a packed column and its heat and mass transfer effectiveness. HVAC\&R Research. 2006;12:3-16.

[54] Elsarrag E, Magzoub EE, Jain S. Mass-transfer correlations for dehumidification of air by triethylene glycol in a structured packed column. Industrial \& engineering chemistry research. 2004;43:7676-81.

[55] Patnaik S, Lenz TG, Löf GOG. Performance studies for an experimental solar open-cycle liquid desiccant air dehumidification system. Solar Energy. 1990;44:123-35.

[56] Yin Y, Zhang X, Wang G, Luo L. Experimental study on a new internally cooled/heated dehumidifier/regenerator of liquid desiccant systems. International Journal of Refrigeration. 2008;31:857-66.

[57] Jain S, Dhar PL, Kaushik SC. Experimental studies on the dehumidifier and regenerator of a liquid desiccant cooling system. Applied Thermal Engineering. 2000;20:253-67.

[58] Qi R, Lu L, Qin F. Model development for the wetted area of falling film liquid desiccant airconditioning system. International Journal of Heat and Mass Transfer. 2014;74:206-9.

[59] Kim J-K, Park CW, Kang YT. The effect of micro-scale surface treatment on heat and mass transfer performance for a falling film $\mathrm{H} 2 \mathrm{O} / \mathrm{LiBr}$ absorber. International Journal of Refrigeration. $2003 ; 26: 575-85$.

[60] Yin Y, Qian J, Zhang X. Recent advancements in liquid desiccant dehumidification technology. Renewable and Sustainable Energy Reviews. 2014;31:38-52.

[61] Saman WY, Alizadeh S. An experimental study of a cross-flow type plate heat exchanger for dehumidification/cooling. Solar Energy. 2002;73:59-71.

[62] Liu X, Chang X, Xia J, Jiang Y. Performance analysis on the internally cooled dehumidifier using liquid desiccant. Building and Environment. 2009;44:299-308. 
[63] Ali A, Vafai K, Khaled AR. Comparative study between parallel and counter flow configurations between air and falling film desiccant in the presence of nanoparticle suspensions. International Journal of Energy Research. 2003;27:725-45.

[64] Koronaki I, Christodoulaki R, Papaefthimiou V, Rogdakis E. Critical review of coupled heat and mass transfer models for a liquid desiccant adiabatic dehumidifier and regenerator. Advances in Building Energy Research. 2014;8:117-36.

[65] Park MS, Howell JR, Vliet GC, Peterson J. Numerical and experimental results for coupled heat and mass transfer between a desiccant film and air in cross-flow. International Journal of Heat and Mass Transfer. 1994;37, Supplement 1:395-402.

[66] Deng S, Ma W. Experimental studies on the characteristics of an absorber using LiBr/H $2 \mathrm{O}$ solution as working fluid. International Journal of Refrigeration. 1999;22:293-301.

[67] Yin Y, Zhang X, Peng D, Li X. Model validation and case study on internally cooled/heated dehumidifier/regenerator of liquid desiccant systems. International journal of thermal sciences. 2009;48:1664-71.

[68] Khan AY. Cooling and dehumidification performance analysis of internally-cooled liquid desiccant absorbers. Applied Thermal Engineering. 1998;18:265-81.

[69] Saman WY, Alizadeh S. Modelling and performance analysis of a cross-flow type plate heat exchanger for dehumidification/cooling. Solar Energy. 2001;70:361-72.

[70] Alizadeh S. Performance of a solar liquid desiccant air conditioner - An experimental and theoretical approach. Solar Energy. 2008;82:563-72.

[71] Saman W, Alizadeh S. An experimental study of a cross-flow type plate heat exchanger for dehumidification/cooling. Solar Energy. 2002;73:59-71.

[72] Riffat S. International patent PCT/GB96/02704. University of Nottingham, UK. 1996.

[73] Shehata HA. HVAC systems using flexible fibre impeller fans [PhD Thesis]: University of Nottingham; 1999.

[74] Oliveira AC, Afonso CF, Riffat SB, Doherty PS. Thermal performance of a novel air conditioning system using a liquid desiccant. Applied Thermal Engineering. 2000;20:1213-23.

[75] Lowenstein A, Slayzak S, Kozubal E. A zero carryover liquid-desiccant air conditioner for solar applications. ASME 2006 International Solar Energy Conference. Colorado, USA.2006. p. 397-407. [76] Mehta J. Regeneration of liquid desiccant using solar energy. 1st International Conference on Non Conventional Energy (ICONCE). Kalyani, India: IEEE; 2014. p. 47-51.

[77] Bergero S, Chiari A. On the performances of a hybrid air-conditioning system in different climatic conditions. Energy. 2011;36:5261-73.

[78] Huang S-M, Zhang L-Z, Pei L-X. Transport Phenomena in a Cross-Flow Hollow Fibre Membrane Bundle Used for Liquid Desiccant Air Dehumidification. Indoor and Built Environment. 2013;22:559-74.

[79] Zhang L-Z, Huang S-M, Pei L-X. Conjugate heat and mass transfer in a cross-flow hollow fiber membrane contactor for liquid desiccant air dehumidification. International journal of heat and mass transfer. 2012;55:8061-72.

[80] Huang S-M, Zhang L-Z, Yang M. Conjugate heat and mass transfer in membrane parallel-plates ducts for liquid desiccant air dehumidification: Effects of the developing entrances. Journal of Membrane Science. 2013;437:82-9.

[81] Moghaddam DG, LePoudre P, Ge G, Besant RW, Simonson CJ. Small-scale single-panel liquidto-air membrane energy exchanger (LAMEE) test facility development, commissioning and evaluating the steady-state performance. Energy and Buildings. 2013;66:424-36.

[82] Huang S-M, Zhang L-Z, Tang K, Pei L-X. Fluid flow and heat mass transfer in membrane parallel-plates channels used for liquid desiccant air dehumidification. International Journal of Heat and Mass Transfer. 2012;55:2571-80. 
[83] Ge G, Ghadiri Moghaddam D, Namvar R, Simonson CJ, Besant RW. Analytical model based

performance evaluation, sizing and coupling flow optimization of liquid desiccant run-around membrane energy exchanger systems. Energy and Buildings. 2013;62:248-57.

[84] Ge G, Moghaddam DG, Abdel-Salam AH, Besant RW, Simonson CJ. Comparison of experimental data and a model for heat and mass transfer performance of a liquid-to-air membrane energy exchanger (LAMEE) when used for air dehumidification and salt solution regeneration. International Journal of Heat and Mass Transfer. 2014;68:119-31.

[85] Hemingson HB, Simonson CJ, Besant RW. Steady-state performance of a run-around membrane energy exchanger (RAMEE) for a range of outdoor air conditions. International Journal of Heat and Mass Transfer. 2011;54:1814-24.

[86] Abdel-Salam AH, Ge G, Simonson CJ. Performance analysis of a membrane liquid desiccant airconditioning system. Energy and Buildings. 2013;62:559-69.

[87] Zhang L-Z. Heat and mass transfer in a randomly packed hollow fiber membrane module: A fractal model approach. International Journal of Heat and Mass Transfer. 2011;54:2921-31. [88] Zhang L-Z, Huang S-M, Chi J-H, Pei L-X. Conjugate heat and mass transfer in a hollow fiber membrane module for liquid desiccant air dehumidification: A free surface model approach. International Journal of Heat and Mass Transfer. 2012;55:3789-99.

[89] Huang S-M, Yang M. Heat and mass transfer enhancement in a cross-flow elliptical hollow fiber membrane contactor used for liquid desiccant air dehumidification. Journal of Membrane Science. 2014;449:184-92.

[90] Zhang L-Z, Huang S-M, Zhang W-B. Turbulent heat and mass transfer across a hollow fiber membrane bundle considering interactions between neighboring fibers. International Journal of Heat and Mass Transfer. 2013;64:162-72.

[91] Huang S-M, Zhang L-Z. Researches and trends in membrane-based liquid desiccant air dehumidification. Renewable and Sustainable Energy Reviews. 2013;28:425-40.

[92] Das RS, Jain S. Experimental performance of indirect air-liquid membrane contactors for liquid desiccant cooling systems. Energy. 2013;57:319-25.

[93] Li Z-X, Zhong T-S, Niu J-L, Xiao F, Zhang L-Z. Conjugate heat and mass transfer in a total heat exchanger with cross-corrugated triangular ducts and one-step made asymmetric membranes.

International Journal of Heat and Mass Transfer. 2015;84:390-400.

[94] Sethi VP, Sharma SK. Thermal modeling of a greenhouse integrated to an aquifer coupled cavity flow heat exchanger system. Solar Energy. 2007;81:723-41.

[95] Xuan YM, Xiao F, Niu XF, Huang X, Wang SW. Research and application of evaporative cooling in China: A review (I) - Research. Renewable and Sustainable Energy Reviews. 2012;16:3535-46.

[96] Watt JR, Brown WK. Evaporative air conditioning Handbook. 3 ed. Lilburn, USA: The Fairmont Press Inc; 1997.

[97] Riangvilaikul B, Kumar S. An experimental study of a novel dew point evaporative cooling system. Energy and Buildings. 2010;42:637-44.

[98] Duan Z, Zhan C, Zhang X, Mustafa M, Zhao X, Alimohammadisagvand B, et al. Indirect evaporative cooling: Past, present and future potentials. Renewable and Sustainable Energy Reviews. 2012;16:6823-50.

[99] Rey Martínez FJ, Velasco Gómez E, Martín García C, Sanz Requena JF, Navas Gracia LM, Hernández Navarro S, et al. Life cycle assessment of a semi-indirect ceramic evaporative cooler vs. a heat pump in two climate areas of Spain. Applied Energy. 2011;88:914-21.

[100] Heidarinejad G, Moshari S. Novel modeling of an indirect evaporative cooling system with cross-flow configuration. Energy and Buildings. 2015;92:351-62. 
[101] Martín RH. Numerical simulation of a semi-indirect evaporative cooler. Energy and Buildings. 2009;41:1205-14.

[102] Gao WZ, Cheng YP, Jiang AG, Liu T, Anderson K. Experimental investigation on integrated liquid desiccant - Indirect evaporative air cooling system utilizing the Maisotesenko - Cycle. Applied Thermal Engineering. 2015;88:288-96.

[103] Anisimov S, Pandelidis D, Jedlikowski A, Polushkin V. Performance investigation of a M (Maisotsenko)-cycle cross-flow heat exchanger used for indirect evaporative cooling. Energy. 2014;76:593-606.

[104] Lee J, Lee D-Y. Experimental study of a counter flow regenerative evaporative cooler with finned channels. International Journal of Heat and Mass Transfer. 2013;65:173-9.

[105] La D, Li Y, Dai YJ, Ge TS, Wang RZ. Development of a novel rotary desiccant cooling cycle with isothermal dehumidification and regenerative evaporative cooling using thermodynamic analysis method. Energy. 2012;44:778-91.

[106] Pandelidis D, Anisimov S, Worek WM. Comparison study of the counter-flow regenerative evaporative heat exchangers with numerical methods. Applied Thermal Engineering. 2015;84:211-24. [107] Zhao X, Li JM, Riffat SB. Numerical study of a novel counter-flow heat and mass exchanger for dew point evaporative cooling. Applied Thermal Engineering. 2008;28:1942-51.

[108] Pandelidis D, Anisimov S. Numerical analysis of the heat and mass transfer processes in selected M-Cycle heat exchangers for the dew point evaporative cooling. Energy Conversion and Management. 2015;90:62-83.

[109] Zhan C, Duan Z, Zhao X, Smith S, Jin H, Riffat S. Comparative study of the performance of the $\mathrm{M}$-cycle counter-flow and cross-flow heat exchangers for indirect evaporative cooling - Paving the path toward sustainable cooling of buildings. Energy. 2011;36:6790-805.

[110] Cui X, Chua KJ, Yang WM, Ng KC, Thu K, Nguyen VT. Studying the performance of an improved dew-point evaporative design for cooling application. Applied Thermal Engineering. 2014;63:624-33.

[111] Zhan C, Zhao X, Smith S, Riffat SB. Numerical study of a M-cycle cross-flow heat exchanger for indirect evaporative cooling. Building and Environment. 2011;46:657-68.

[112] Cui X, Chua KJ, Yang WM. Numerical simulation of a novel energy-efficient dew-point evaporative air cooler. Applied Energy. 2014;136:979-88.

[113] Liu XH, Jiang Y, Chang XM, Yi XQ. Experimental investigation of the heat and mass transfer between air and liquid desiccant in a cross-flow regenerator. Renewable Energy. 2007;32:1623-36. [114] Gandhidasan P. Quick performance prediction of liquid desiccant regeneration in a packed bed. Solar Energy. 2005;79:47-55.

[115] Mei L, Dai YJ. A technical review on use of liquid-desiccant dehumidification for airconditioning application. Renewable and Sustainable Energy Reviews. 2008;12:662-89.

[116] Elsarrag E, Abdalla K. Effectiveness and Performance of a Counterflow Liquid Desiccant Regeneration Tower in a Hot-Humid Climate. ASHRAE Transactions. 2009;115. [117] Mehta JR, Rane MV. Liquid Desiccant based Solar Air Conditioning System with Novel Evacuated Tube Collector as Regenerator. Procedia Engineering. 2013;51:688-93.

[118] Moghaddam DG, Besant RW, Simonson CJ. Solution-side effectiveness for a liquid-to-air membrane energy exchanger used as a dehumidifier/regenerator. Applied Energy. 2014;113:872-82. [119] Martin V, Goswami D. Heat and mass transfer in packed bed liquid desiccant regenerators-an experimental investigation. Journal of Solar Energy Engineering. 1999;121:162-70.

[120] Longo GA, Gasparella A. Experimental analysis on desiccant regeneration in a packed column with structured and random packing. Solar Energy. 2009;83:511-21.

[121] Elsarrag E. Performance study on a structured packed liquid desiccant regenerator. Solar Energy. 2006;80:1624-31. 
[122] Ren CQ, Tu M, Wang HH. An analytical model for heat and mass transfer processes in internally cooled or heated liquid desiccant-air contact units. International Journal of Heat and Mass Transfer. 2007;50:3545-55.

[123] Yin Y, Zhang X. Comparative study on internally heated and adiabatic regenerators in liquid desiccant air conditioning system. Building and Environment. 2010;45:1799-807.

[124] Peng D, Zhang X. Modeling and simulation of solar collector/regenerator for liquid desiccant cooling systems. Energy. 2011;36:2543-50.

[125] Zeidan E-SB, Aly AA, Hamed AM. Modeling and simulation of solar-powered liquid desiccant regenerator for open absorption cooling cycle. Solar Energy. 2011;85:2977-86.

[126] Nelson D, Wood B. Evaporation rate model for a natural convection glazed collector/regenerator. Journal of Solar Energy Engineering. 1990;112:51-7.

[127] McCormick P, Brown S, Tucker S. Performance of a glazed open flow liquid desiccant solar collector for both summer cooling and winter heating: Final report. Lockheed Missiles and Space Co., Inc., Huntsville, AL (USA). Research and Engineering Center; 1983.

[128] Yang R, Wang P-L. The optimum glazing height of a glazed solar collector/regenerator for open-cycle absorption cooling. Energy. 1994;19:925-31.

[129] Yang R, Wang P-L. Experimental study of a forced convection solar collector/regenerator for open-cycle absorption cooling. Journal of solar energy engineering. 1994;116:194-9.

[130] Ji L, Wood B. Performance enhancement study of solar collector/regenerator for open-cycle liquid desiccant regeneration. Proceedings of the American Solar Energy Society Annual Conference. Washington DC, USA. 1993. p. 351-6.

[131] Kabeel AE. Augmentation of the performance of solar regenerator of open absorption cooling system. Renewable Energy. 2005;30:327-38.

[132] Alizadeh S, Saman WY. Modeling and performance of a forced flow solar collector/regenerator using liquid desiccant. Solar Energy. 2002;72:143-54.

[133] Yutong L, Yang H. Experimental study of an open-cycle solar collector/regenerator using liquid desiccant for air conditioning. International journal of green energy. 2010;7:273-88.

[134] Elsarrag E. Evaporation rate of a novel tilted solar liquid desiccant regeneration system. Solar Energy. 2008;82:663-8.

[135] Koronaki I, Christodoulaki R, Papaefthimiou V, Rogdakis E. Preliminary Investigation of a Liquid Desiccant System for Dehumidification and Cooling in Athens. ASME 2013 International Mechanical Engineering Congress and Exposition: American Society of Mechanical Engineers; 2013. p. V06AT7A055-V06AT07A.

[136] Zhang L-Z, Zhang N. A heat pump driven and hollow fiber membrane-based liquid desiccant air dehumidification system: Modeling and experimental validation. Energy. 2014;65:441-51.

[137] Kessling W, Laevemann E, Peltzer M, Bayern Z. Efficient energy storage for desiccant cooling systems. Proceedings of EuroSun 96. Freiburg, Germany. 1996. p. 1254-60.

[138] Laevemann E, Sizmann R. Energy storage in open cycle desiccant cooling systems, comparison of liquid and solid desiccants. Solid Sorption Refrigeration, IIR Congress. Paris, France. 1992. p. 270-5.

[139] Kalogirou SA. Seawater desalination using renewable energy sources. Progress in energy and combustion science. 2005;31:242-81.

[140] Dickinson WC, Cheremisinoff PN. Solar energy technology handbook. New York, USA: Marcel Dekker; 1980.

[141] Al-Mutaz IS, Al-Anezi IA. Determination of Silica Scale Potential in Reverse Osmosis Pretreatment. IDA World Congress on Desalination and Water Re-Use. San Diego, USA. Aug 29 Sept 3, 1999. 
[142] Anderson CC. Limnology of shallow saline mermomistic lake. Limnol Oceanogr 1958;3:25969.

[143] Duffie JA, Beckman WA. Solar Engineering of Thermal Processes. 3 ed: John Wiley \& Sons; 2006.

[144] Tabor H. Solar ponds. Science Journal. 1966;66:66-71.

[145] Weinberger H. The physics of the solar pond. Solar Energy. 1964;8:45-56.

[146] Tabor H, Matz R. Solar pond project. Solar Energy. 1965;9:177-82.

[147] Garg HP. Advances in solar energy technology. Dordecht, Holland: D Reidel Publishing Company; 1987.

[148] Lu H, Swift AH, Hein HD, Walton JC. Advancements in salinity gradient solar pond technology based on sixteen years of operational experience. Journal of solar energy engineering. 2004;126:759-67.

[149] Kreider JF, Kreith F. Solar heating and cooling: Active and passive design. 2 ed. London: Hemisphere Pub. Corp.; 1982.

[150] Garg H. Solar energy: fundamentals and applications: Tata McGraw-Hill Education; 2000.

[151] Dinçer İ, Rosen MA. Exergy: energy, environment and sustainable development. Oxford, UK: Elsevier; 2007.

[152] El-Sebaii A, Ramadan M, Aboul-Enein S, Khallaf A. History of the solar ponds: a review study. Renewable and Sustainable Energy Reviews. 2011;15:3319-25.

[153] Hull JR. Membrane stratified solar ponds. Solar Energy. 1980;25:317-25.

[154] Shaffer LH. Viscosity stabilized solar pond. In: Proc Int Solar Energy Society Congress, 1978. p. 1171-5.

[155] Garg HP. Advances in solar energy technology: collection and storage systems. Dordrecht Holland: D. Reidel Publishing Company; 1987.

[156] Tabor H. Large area solar collectors (solar ponds) for power production. In: UN Conf New Sources of Energy, Publication S/47. Rome. 1961.

[157] Rabl A, Nielsen CE. Solar ponds for space heating. Solar Energy. 1975;17:1-12.

[158] Subhakar D, Murthy SS. Saturated solar ponds: 1. Simulation procedure. Solar Energy. 1993;50:275-82.

[159] Willsie HE. Experiments in the development of power from the sun's heat. Engineering news. 1909;61:511-4.

[160] Hull JR. Salinity gradient solar ponds. Boca, Raton, Florida: CRC Press; 1988.

[161] Date A, Akbarzadeh A. Salinity Gradient Solar Ponds. Solar Energy Sciences and Engineering Applications ed. Balkema, The Netherlands: CRC Press; 2014.

[162] Akbarzzadeh A, Andrews J, Golding P. Solar Ponds. In Solar Energy Conversion And Photoenergy Systems. Oxford, UK: EOLSS Publishers; 2008.

[163] Tabor H, Doron B. Solar ponds-lessons learned from the $150 \mathrm{~kW}$ (e) power plant at Ein Boqek. Proceedings of the ASME Solar Energy Div,. Anaheim, California, USA. 1986. p. 344.

[164] Lodhi MAK. Solar ponds in alkaline lake and oil well regions. Energy conversion and management. 1996;37:1677-94.

[165] Chinn A, Akbarzadeh A, Dixon C. The Design, Construction, Operation \& Maintenance of an Experimental Magnesium Chloride Solar Pond. Destination Renewables-from Research to Market: Proceedings of the 41 st Annual Conference of the Australian and New Zealand Solar Energy Society. Melbourne, Australia. November, 2003. p. 329-38.

[166] Sherman BS, Imberger J. Control of a solar pond. Solar Energy. 1991;46:71-81.

[167] Kumar A, Kishore V. Construction and operational experience of a $6000 \mathrm{~m} 2$ solar pond at Kutch, India. Solar energy. 1999;65:237-49. 
[168] Al-Marafie A, Al-Homoud A, Al-Kandari A, Abou-Seido E. Performance of $1700 \mathrm{~m} 2$ solar pond operation in arid zone. International Journal of Energy Research. 1991;15:535-48. 